\title{
NATURE IS SMARTER THAN WE ARE: MIDWIFERY AND THE RESPONSIVE STATE
}

\section{JENNIFER HICKEY*}

"Many of our problems in US maternity care stem from the fact that we leave no room for recognizing when nature is smarter than we are."

—Ina May Gaskin, Birth Matters: A Midwife’s Manifesta

\section{INTRODUCTION}

The United States was recently dubbed "the most dangerous place in the developed world to give birth." Over seven hundred pregnant women or new mothers die in the United States each year. ${ }^{2}$ Infants are dying at an alarming rate as well. ${ }^{3}$ Our shockingly high and ever-increasing rate of maternal mortality, particularly among Black women, has garnered significant national attention. Further, many women experience mistreatment at the hands of their health care providers, including the imposition of unnecessary or unwanted medical interventions during birth. Aside from causing emotional and physical trauma, such interventions have been directly linked to increased maternal mortality. ${ }^{4}$

\footnotetext{
* Postdoctoral Fellow, Vulnerability and Human Condition Initiative, Emory University School of Law. I would like to thank Professor Martha Fineman for her thoughtful feedback and my amazing home birth midwives for the inspiration.

${ }^{1}$ Alison Young, Hospitals Know How to Protect Mothers. They Just Aren 't Doing It., USA TodAY (Nov. 14, 2019), https://www.usatoday.com/in-depth/news/investigations/deadly-deliveries/2018/07/26/maternalmortality-rates-preeclampsia-postpartum-hemorrhage-safety/546889002/ [https://perma.cc/7X9A-GTXJ].

${ }^{2} I d$.

${ }^{3}$ In 2017, 5.8 of 1,000 live births resulted in infant death. Infant Mortality Rates, ORG. FOR ECON. CoOP. \& DEV. (OECD), https://data.oecd.org/healthstat/infant-mortality-rates.htm [https://perma.cc/747N-5D9Q].

${ }^{4}$ See, e.g., Debra Bingham et al., Maternal Mortality in the United States: A Human Rights Failure, 83 CONTRACEPTION 189, 191 (2011) (arguing that overuse of medical procedures increases severe maternal injuries). See generally Walid M. Fahmy et al., Association Between Maternal Death and Cesarean Section in Latin America: A Systematic Literature Review, 59 MIDWIFERY 88 (2018) (reporting several studies indicating that cesarean section significantly increases chances of maternal death compared to vaginal birth).
} 
The state has done little to address or even examine the underlying systemic causes of this harm, particularly the role of medicalization. Birth in the United States is overwhelmingly medicalized and socially and culturally positioned as a high-risk condition in need of medical intervention, rather than a naturally occurring process in need of social support. The United States is among a small number of industrialized nations that use physicians, rather than midwives, as the primary care providers for lowrisk births, ${ }^{5}$ yet our maternal mortality rates are significantly higher. ${ }^{6}$ And women who birth with midwives experience far fewer interventions and better overall treatment. Instead of taking steps to support midwifery and normalize birth without intervention, the state allows medical professionals to discredit and suppress midwifery and sometimes actively participates in this campaign by criminalizing out-of-hospital birth. In sum, the United States is failing birthing women.

Birth in the United States is overwhelmingly considered a private matter between a woman and her doctor. The perceived autonomous nature of the doctor-patient relationship, coupled with the rise of medical consumerism, functions to absolve the state of its responsibility for birth. Additionally, birth is framed as the product of individual choice, which further allows the state to ignore positive obligations towards birthing women and instead facilitates punitive responses when a woman makes the "wrong" choice that may harm her fetus. The legal and social framing of birth injury as a violation of individual rights obscures the state's responsibility to address birth injury as a social harm necessitating response and reform to societal institutions. Such reform necessarily includes addressing the harm caused by excessive medicalization.

Scholars and advocates arguing for greater state support of midwifery typically ground their theories for state responsibility in regulation of unfair market practices or improved support of maternal decision making. ${ }^{7}$ Unfortunately, these arguments only

\footnotetext{
${ }^{5}$ See Marsden Wagner, Midwifery in the Industrialized World, 20 J. Soc'y OBSTETRICIANS \& GYNAECOLOGISTS CAN. 1225, 1225 (1998) [hereinafter Wagner, Midwifery in the Industrialized World] ("In nearly every industrialized country outside North America, midwives provide primary maternity care, and obstetricians, generally, are hospital-based specialists providing tertiary maternity care.”).

${ }^{6}$ U.S. maternal mortality rates are higher than most developed countries'. See WORLD HEALTH ORG. (WHO), TRENDS IN MATERnal MoRTALITy 2000 to 2017: Estimates By WHO, UNICEF, UNFPA, WORLD BANK Group and the United Nations Population Division, Executive Summary (2019) [hereinafter WHO, TRENDS IN MATERNAL MORTALITY], https://apps.who.int/iris/bitstream/handle/10665/327596/WHO-RHR19.23-eng.pdf?sequence=13\&isAllowed=y [https://perma.cc/62ZN-G7CG].

${ }^{7}$ See, e.g., Leia Dingott, Pushing for Change: The State of Arizona Should Allow Women Greater Access to Midwifery Care, 49 ARIZ. ST. L.J. 433, 436 (2017) (arguing for improvements in state law to better support
} 
further confine the state and society to their limited roles. This Article instead argues for a responsive state that affirmatively provides a meaningful and safe birthing experience to all women by nature of its obligation to provide its citizens with the tools needed for resiliency. ${ }^{8}$ This entails recognizing that birth is not a private event, but rather a social one, stemming from our collective responsibility for societal reproduction. Thus, the state is obligated to recognize and remedy the widespread social harm caused by medicalization of birth.

Part I provides a comprehensive overview of medicalized birth in the United States and its attendant problems. Part II explores the many benefits of midwifery in addressing these issues and the current constraints on the midwifery profession. Part III discusses the state's limited and problematic attempts to address birth injury. Part IV explores how the medical and cultural privatization of birth as the product of individual choice forecloses meaningful state response, examining birth in the time of COVID-19 as a salient example. Part $\mathrm{V}$ then concludes by establishing a better approach to state responsibility that obligates the state to actively promote non-medicalized birth.

\section{Birth in the United States}

Birth in the United States today is a product of social, cultural, and clinical norms and practices that have shifted dramatically over time. While now overwhelmingly considered a medical event, childbirth was not always confined to hospital rooms. For centuries, birth in the United States predominantly took place in the home, aided by midwives and community members. ${ }^{9}$ Birth was considered a natural, celebratory process rather than a pathological event requiring medical intervention. With rapid speed, pregnancy in the United States transformed both socially and clinically into the overwhelmingly dominant medical model of today. While nearly every other

midwifery and respect maternal decision-making); Sarah A. Stover, Born by the Woman, Caught by the Midwife: The Case for Legalizing Direct-Entry Midwifery in All Fifty States, 21 HeALTH MaTRIX 307,311 (2011) (arguing that the state's power to regulate health professionals must be balanced against parental choice of birth provider); Chris Hafner-Eaton \& Laurie K. Pearce, Birth Choices, the Law, and Medicine: Balancing Individual Freedoms and Protection of the Public's Health, 19 J. HeALTH POL. POL'Y \& L. 813, 813 (1994).

${ }^{8}$ As discussed in Part V, this argument for state responsibility for birth is based in vulnerability theory, as developed by Professor Martha Fineman. See, e.g., Martha Albertson Fineman, The Vulnerable Subject and the Responsive State, 60 EMORY L.J. 251, 268 (2010) [hereinafter Fineman, The Vulnerable Subject and the Responsive State].

${ }^{9}$ Richard W. Wertz \& Dorothy C. Wertz, Lying-in: A History of Childbirth in America 1 (Yale Univ. Press expanded ed. 1989) (1977). 
industrialized nation eschews medical intervention for the vast majority of births, hospital birth attended by trained surgeons is the norm in the United States. ${ }^{10}$ The powerful rhetoric of pregnancy as a high-risk event in need of medical management both stems from and perpetuates this hegemonic model of birth. At the same time, infant mortality rates are shockingly high compared to other countries. Maternal mortality rates are alarmingly high and continuing to rise. Women are increasingly facing mistreatment at the hands of their health care providers and suffering the real and lasting effects of birth trauma.

This overview of birth in the United States begins with a history of the transformation of childbirth in the United States from a natural process to a medical event. It next discusses the infant and maternal mortality crises and the ways in which they are furthered by excessive medicalization. It concludes with an examination of the increasing mistreatment of birthing women by medical professionals.

\section{A. Medicalization of Birth}

The story of birth in the United States is one of rapid transformation. For hundreds of years, women gave birth in their homes with the assistance of midwives and without medical intervention. ${ }^{11}$ In just half a century, clinical and social attitudes shifted dramatically to regard pregnancy and birth as a medical condition that must be managed, rather than as a naturally occurring process. ${ }^{12}$ As a result, hospital births attended by physicians quickly became the dominant model of care.

\section{Communal Childbirth}

Birth in the United States began as a non-medical communal experience and remained that way for centuries. In colonial America, women gave birth in their homes with the aid of the community. ${ }^{13}$ Midwives were the primary skilled birth attendants for a

\footnotetext{
${ }^{10}$ See Wagner, Midwifery in the Industrialized World, supra note 5, at 1225; Marsden S. Wagner, Infant Mortality in Europe: Implications for the United States: Statement to the National Commission to Prevent Infant Mortality, 9 J. Pub. Health PoL'y 473, 480 (1988) [hereinafter Wagner, Infant Mortality in Europe] (finding most European countries use midwives as primary care providers for low-risk women).

${ }^{11}$ WERTZ \& WeRTZ, supra note 9 , at 1.

${ }^{12}$ Stacey A. Tovino, American Midwifery Litigation and State Legislative Preferences for PhysicianControlled Childbirth, 11 CARDOZo WOMEN's L.J. 61, 63 (2004).

${ }^{13}$ WERTZ \& WERTZ, supra note 9, at 1.
} 
large percentage of births in the United States from the colonial period to the Great Depression. ${ }^{14}$ Physicians began practicing obstetrics as early as the second half of the eighteenth century, but they initially participated in only the most difficult births. ${ }^{15}$ The simplicity of early medicine allowed for cooperation between midwives and physicians for much of the eighteenth century. ${ }^{16}$

\section{Rise of the Physician}

In the late eighteenth century, perceptions began to shift, and women started hiring physicians to attend their low-risk births. ${ }^{17}$ Many thought that American physicians, trained abroad or through apprenticeships, would be able to offer services that midwives could not because of their formal education. ${ }^{18}$ Additionally, physicians were able to administer opium and use forceps, technological advances that were thought to improve birth outcomes. ${ }^{19}$

At the same time, the medical profession was becoming more exclusive. ${ }^{20}$ Male physicians who once practiced as a pastime or second career began devoting more time to the profession, while changing social notions dictated that women were ill-suited to provide obstetric care. ${ }^{21}$ Thus, "the status advantages of [a male physician's] gender" and the "popular image of superior education" combined to perpetuate the notion that physicians could provide a safer and more comfortable birth experience than midwives. ${ }^{22}$

\footnotetext{
${ }^{14}$ Charlotte G. Borst, Catching Babies: The Professionalization of Childbirth, 1870-1920, at 1 (1995).

${ }^{15}$ Judith Walzer Leavitt, Brought to Bed: Child-Rearing in America, 1750-1950, at 38 (1986).

${ }^{16}$ Tovino, supra note 12 , at 63-64.

${ }^{17}$ LEAVITT, supra note 15 , at 39.

${ }^{18}$ Tovino, supra note 12, at 64.

${ }^{19}$ LeAvitT, supra note 15 , at 39.

${ }^{20}$ Tovino, supra note 12 , at 65.

${ }^{21}$ See id. at 63-67.

${ }^{22}$ LeAvitT, supra note 15 , at 39.
} 
This burgeoning "exclusivity of the medical profession" inevitably led to tension between physicians and midwives. ${ }^{23}$ Those suddenly practicing medicine full-time found themselves competing with midwives for patients. This economic competition undoubtedly spurred efforts to discredit midwifery as primitive and unsafe, a campaign that continues to this day. ${ }^{24}$ Additionally, medical professionals relied on racial and ethnic stereotypes to discredit midwifery throughout the nineteenth and early twentieth centuries. At the time, midwives attended a large majority of births for Black and immigrant families. ${ }^{25}$ In numerous anti-midwifery statements released during this time, health professionals denigrated midwives as "ignorant, untrained" foreigners ${ }^{26}$ or "superstitious negro[es]"27 who practiced in "filthy" and "unhealthy" environments. ${ }^{28}$ The image of the dirty ignorant midwife was subsequently propagated by a number of women's magazines. ${ }^{29}$ This campaign against midwives of color had a profound suppressive effect on the entire midwifery profession. ${ }^{30}$

\footnotetext{
${ }^{23}$ Tovino, supra note 12 , at 65 .

${ }^{24}$ See infra Part II.B.2 for a more detailed discussion.

25 Judy B. Litoff, American Midwives: 1860 to the Present 27 (1978).

${ }^{26}$ See id. at 51 (discussing a 1906 study by a public health committee that stated "the majority of so-called midwives are foreigners of a low grade-ignorant, untrained women."); see also GERTRUDE JACINTA FRASER, African American Midwifery in the South: Dialogues of Birth, RACE ANd Memory 51 (1998) (discussing a 1925 physician statement at a conference that "it would seem to be poor judgment to attempt to make competent obstetricians out of the great army of ignorant women now practicing midwifery in this country").
}

${ }^{27}$ LitofF, supra note 25, at 75 (discussing a Virginia study stating that doctors did not want to "deal with the ignorant and superstitious negro [midwife]").

${ }^{28}$ FRASER, supra note 26, at 78 (discussing a statement by a Mississippi health administrator in the 1920s referring to midwives as "filthy and ignorant, and not far removed from the jungles of Africa, laden with its atmosphere of weird superstition and voodooism"); $i d$. at 91 (discussing a physician statement in 1928 referring to midwives as "very ignorant and dirty creatures"); Tovino, supra note 12, at 105 (discussing physicians' use of stereotypes regarding the "unhealthy living environments" of Black and immigrant families to discredit midwifery).

${ }^{29}$ See Danielle Thompson, Midwives and Pregnant Women of Color: Why We Need to Understand Intersectional Changes in Midwifery to Reclaim Home Birth, 6 COLUM. J. RACE \& L. 27, 31-32 (2016) (collecting quotes from early-twentieth century women's magazines).

${ }^{30}$ Tovino, supra note 12 , at 105. 
The powerful effect of this discourse cannot be overstated. Evidence available at the time simply did not support the notion that physician-assisted birth was safer, yet its popularity among middle- and upper-class women continued to rise. In fact, many historians believe that nineteenth-century physicians may have increased maternal mortality. ${ }^{31}$ These physicians experienced a host of complications in their obstetric practices, caused in part by the unnecessary and inappropriate use of medical interventions such as bloodletting, drugs, and forceps. ${ }^{32}$ At the very least, birth outcomes did not improve with physicians rather than midwives in attendance. ${ }^{33}$ For example, a medical professor conducted a study of U.S. obstetrical training in 1912 and concluded that physicians were just as much to blame for high rates of maternal mortality as midwives ${ }^{34}$ Subsequent improvements in maternal mortality in the early twentieth century were primarily due to simple measures aimed at reducing germ transmission, such as handwashing and the use of antiseptics. ${ }^{35}$ Such measures hardly required formal medical training and could easily have been used by midwives in the home. Nonetheless, many women believed that medical and technological advancement would provide a superior birth experience. ${ }^{36}$

This elevation of the authoritative white male physician undoubtedly contributed to the individualization of birth as well. For much of the nineteenth century, even physicianassisted birth was communal. Members of the community continued to assist with birth at home and childbirth was still predominantly a social event. ${ }^{37}$ However, tensions often developed between physicians and communal birth attendants, each suspicious of the other's practices. ${ }^{38}$ Surely this tension reduced the number of birth attendants and provided physicians with a strong impetus to seek out private labor rooms. In this environment, a shift from home birth to hospital birth seemed inevitable.

${ }^{31}$ Laurel Thatcher Ulrich, A Midwife's Tale: The Life of Martha Ballard, Based on Her Diary, 1785-1812, at 170-71 (1991).

${ }^{32}$ LeAvitT, supra note 15 , at $43-48$.

${ }^{33}$ ULRICH, supra note 31, at 57.

${ }^{34}$ LEAVITT, supra note 15 , at 63.

${ }^{35}$ LitoFf, supra note 25, at 19-20.

${ }^{36}$ LEAVITT, supra note 15 , at 58.

${ }^{37} I d$. at 59 .

${ }^{38} \mathrm{Id}$. at $60-61$. 


\section{From Home to Hospital}

In the twentieth century, birth moved rapidly from the home to the hospital. As late as 1900, midwife-attended home births accounted for approximately one-half of all births in the United States. ${ }^{39}$ This number was higher in communities of color and remained so throughout the last half of the twentieth century. ${ }^{40}$ But by $1940,55 \%$ of births in the U.S. occurred in the hospital. ${ }^{41}$ By $1950,88 \%$ of births occurred in the hospital. ${ }^{42}$ After 1950, physicians attended more than $80 \%$ of deliveries in the U.S. ${ }^{43}$

The same notions used to elevate physician over midwife served to elevate hospital over home. The dramatic shift to hospital birth was caused by theories regarding germ transmission in the home, popular medical and women's journals encouraging women to deliver babies in the hospital for safety and health benefits, middle- and upper-class women's desire for pain management, and the desire for more "efficient" birthing experiences. $^{44}$

Nonetheless, hospitals did not necessarily provide a superior birth experience. Instead, the warm comfortable home was replaced with a cold and sterilized environment. ${ }^{45}$ Throughout the 1950 s, women were expected to be passive during birth and were often denied the information necessary to make choices regarding the birth

${ }^{39} I d$. at 12.

${ }^{40}$ George W. Lowis \& Peter G. McCaffery, Sociological Factors Affecting the Medicalization of Midwifery, in Midwifery and the Medicalization of Childbirth: Comparative Perspectives 5, 24 (Edwin R. van Teijlingen et al. eds., 2000).

${ }^{41}$ LEAVITT, supra note 15, at 171.

${ }^{42} I d$.

${ }^{43} I d$. at 12 .

${ }^{44}$ See Tovino, supra note 12, at 67; Jamie R. Abrams, Distorted and Diminished Tort Claims for Women, 34 CARdozo L. Rev. 1955, 1966 (2013) (discussing reasons for the shift from homebirth to hospital births).

${ }^{45}$ Marc A. Rodwin, Patient Accountability and Quality of Care: Lessons from Medical Consumerism and the Patients' Rights, Women's Health and Disability Rights Movements, 20 AM. J.L. \& MED. 147, 158 (1994) (discussing the "cold medicalized surrounding" of 1950s hospital birth). 
experience. ${ }^{46} \mathrm{~A}$ woman insisting on natural childbirth was considered "hostile. ${ }^{47}$ Women were sometimes physically isolated and even restrained. ${ }^{48}$ Birth was often induced or delayed in accordance with the physician's schedule. ${ }^{49}$ Parents frequently waited hours to hold their newborns for the first time. ${ }^{50}$ Physicians performed medically unnecessary interventions such as delivery by forceps and cesareans. ${ }^{51}$ Birth had become "a kind of industrial production far removed from the comforts of social childbirth;" an experience many women found "unpleasant and alienating." ${ }^{.52}$ By 1970, this transformation culminated in the rebranding of "natural birth" to include such medical interventions as episiotomy, outlet forceps, Demerol, and epidural anesthesia. ${ }^{53}$

1970s feminism spawned a brief "revolution" against this medicalized birth experience. Feminists began to question the imbalance of power present in hospital births. ${ }^{54}$ Many asserted that this "medicalization of birth" was based on patriarchal control over women's bodies. ${ }^{55}$

\footnotetext{
${ }^{46} \mathrm{Id}$.

${ }^{47}$ WERTZ \& WERTZ, supra note 9, at 191.

${ }^{48}$ Rodwin, supra note 45 , at 158 .

${ }^{49} \mathrm{Id}$.

${ }^{50} \mathrm{Id}$.

${ }^{51} I d$.

${ }^{52}$ WERTZ \& WERTZ, supra note 9, at 173.

${ }^{53} I d$. at 195.
}

${ }^{54}$ See Rodwin, supra note 45, at 158 (listing the "demeaning and derogatory manner" in which doctors treated their patients during birth as an area of concern for the mid-1960s women's health movement).

${ }^{55}$ See Jessica C. A. Shaw, The Medicalization of Birth and Midwifery as Resistance, 34 HeAlth CARE FOR WOMEN INT'L 522, 523 (2013) (discussing the medicalization of women's bodies in relation to the patriarchy); Rodwin, supra note 45, at 159 (discussing a concern of the mid-1960s women's health movement that "medicine has been used to control their reproductive and sexual choices, foster stereotypes, and keep women in their place"); WERTZ \& WERTZ, supra note 9, at 194 (noting the "idea of regaining control over one's body" during birth became a "major tenet of the women's liberation movement"). 
Despite these objections, more than $98 \%$ of women in the United States today give birth in the hospital, attended by surgeons, under the medical model of childbirth. ${ }^{56}$ This medical norm of clinical birth is mutually reinforced by social norms. "The medicalized birth is [now] so ingrained in our society that people can think of no other way to frame their experiences." 57 Social construction of birth has invariably shifted from "natural" to "medical." Pregnancy is now understood as "risk" that must be managed through medical intervention. ${ }^{58}$ Scholars have situated this view within the larger context of our "risk society," in which individuals increasingly view day-to-day activities through the lens of risk and risk management. ${ }^{59}$

Thus, childbirth in the United States has undeniably transitioned from a natural physical process to a condition or illness that must be treated through medical intervention. Once a celebratory event, birth in the United States is now increasingly pathological, mechanical, stressful, and isolated.

\section{B. Maternal and Infant Mortality and Morbidity}

Unfortunately, increasing medical treatment of pregnancy and birth has not led to better outcomes for mothers or infants. The United States is one of a small number of industrialized nations to use physicians, rather than midwives, as the primary care providers for low-risk births, ${ }^{60}$ but has been dubbed "the most dangerous place to give birth in the developed world."

\footnotetext{
${ }^{56}$ Marian F. MacDorman \& Eugene Declercq, Trends and State Variations in Out-of-Hospital Births in the United States, 2004-2017, 46 BIRTH 279, 280 (2019) (providing statistics on the percentage of hospital births in the United States).

${ }^{57}$ Diana C. Parry, Women's Lived Experiences with Pregnancy and Midwifery in a Medicalized and Fetocentric Context: Six Short Stories, 12 QualitaTIVE InQUIRY 459, 464 (2006) (describing the ingrained nature of medicalized birth).

${ }^{58}$ Laura Purdy, Medicalization, Medical Necessity, and Feminist Medicine, 15 Bioethics 248, 249 (2001) (explaining medicalization of women's health).

${ }^{59}$ See Alphia Possamai-Inesedy, Confining Risk: Choice and Responsibility in Childbirth in a Risk Society, 15 Health Socio. Rev. 406, 407-08 (2006) (discussing the concept of risk society); Kirstie Coxon, Jane Sandalla \& Naomi J. Fulopb, To What Extent Are Women Free to Choose Where to Give Birth? How Discourses of Risk, Blame and Responsibility Influence Birth Place Decisions, 16 HeAlth RISK \& Soc'y 51, 54-55 (2014).

${ }^{60}$ See Wagner, Midwifery in the Industrialized World, supra note 5, at 1225.

${ }^{61}$ Young, supra note 1.
} 


\section{Dangerous Birth}

The United States currently has shockingly high rates of infant and maternal mortality. In 2017, 5.8 of 1,000 live births resulted in infant death. ${ }^{62}$ This rate is higher than almost all of the wealthier thirty-five member countries of the Organization for Economic Co-operation and Development (OECD) ${ }^{63}$ Further, over seven hundred pregnant women or new mothers die each year in the United States. ${ }^{64}$ The maternal mortality rate (MMR) in the U.S. is higher than most developed countries, with 19 out of every 100,000 mothers dying from pregnancy and childbirth complications, according to the World Health Organization (WHO) ${ }^{65}$ Other studies have placed the MMR as high as 28 per $100,000 .{ }^{66}$ The U.S. MMR is more than twice that of the United Kingdom and almost twice that of Canada. ${ }^{67}$ Disturbingly, this number has been steadily increasing and more than doubled over the last three decades. ${ }^{68}$ The United States is now the only developed country with an increasing MMR. ${ }^{69}$

Maternal morbidity is an even greater problem in the United States. The Centers for Disease Control and Prevention (CDC) defines severe maternal morbidity as "unexpected outcomes of labor and delivery that result in significant short- or long-term consequences to a woman's health." ${ }^{.70}$ For every maternal death, close to one hundred women suffer a

\footnotetext{
${ }^{62}$ OECD, supra note 3.

${ }^{63}$ Id.; see also Christopher Ingraham, Our Infant Mortality Rate Is a National Embarrassment, WASH. PosT (Sep. 29, 2014), https://www.washingtonpost.com/news/wonk/wp/2014/09/29/our-infant-mortality-rate-is-anational-embarrassment [https://perma.cc/H66W-2WX3].

${ }^{64}$ Young, supra note 1.

${ }^{65}$ WHO, Trends in Maternal Mortality, supra note 6 , at 1,11 .

${ }^{66}$ Nan H. Troiano \& Patricia M. Witcher, Maternal Mortality and Morbidity in the United States: Classification, Causes, Preventability, and Critical Care Obstetric Implications, 32 J. Perinatal \& NeONATAL NuRSING 222, 222 (2018).

${ }^{67}$ WHO, supra note 6 , at 72,76 .

${ }^{68}$ Troiano \& Witcher, supra note 66, at 222.

${ }^{69}$ John A. Ozimek \& Sarah J. Kilpatrick, Maternal Mortality in the Twenty-First Century, 45 OBSTETRICS \& GyNeCOLOGY CLINICS N. AM. 175, 176-77 (2018).

${ }^{70}$ Severe Maternal Morbidity in the United States, Ctrs. For Disease Control \& Prevention (CDC), https://www.cdc.gov/reproductivehealth/maternalinfanthealth/severematernalmorbidity.html [https://perma.cc/8JUF-5JSP] (Jan. 31, 2020).
} 
severe obstetric morbidity. ${ }^{71}$ Like the rate of maternal mortality, the maternal morbidity rate in the U.S. has been steadily increasing. ${ }^{72}$

There are well-documented racial and ethnic disparities in U.S. maternal deaths and morbidities as well. Current studies estimate that Black women are three to four times more likely to die during pregnancy than white women. ${ }^{73}$ Similarly, maternal morbidity rates are higher for racial and ethnic minority women. ${ }^{74}$

The rising MMR in particular has garnered significant public attention. In calling for a solution, experts and commentators tend to focus on potential causes such as systemic racism in the medical profession, ${ }^{75}$ inadequate medical care ${ }^{76}$ and individual health conditions and habits. ${ }^{77}$ Some focus more broadly on underlying social causes such as poverty ${ }^{78}$ These are certainly important factors to consider. But the uniquely medical model of birth in the United States deserves significant scrutiny.

\footnotetext{
${ }^{71}$ Elizabeth A. Howell, Reducing Disparities in Severe Maternal Morbidity and Mortality, 61 CLINICAL OBSTETRICS \& GYNECOLOGY 387, 388 (2018).

${ }^{72} \mathrm{CDC}$, supra note 70 .

${ }^{73}$ Howell, supra note 71, at 387.

${ }^{74} \mathrm{Id}$. at 388 (discussing rates of severe maternal morbidity events).

${ }^{75}$ See, e.g., id. at 394-96. See generally Dána-Ain Davis, Obstetric Racism: The Racial Politics of Pregnancy, Labor, and Birthing, 38 Med. Anthropology 560 (2019) (discussing racism in the obstetric profession and how it affects birth outcomes).
}

${ }^{76}$ See, e.g., Andreea A. Creanga et al., Maternal Mortality and Morbidity in the United States: Where Are We Now?, 23 J. Women's Health 3, 5 (2014) (focusing on cardiovascular conditions); Ozimek \& Kilpatrick, supra note 69 , at $177-80$ (discussing medical causes of death such as hemorrhage, hypertension, and thrombosis).

${ }^{77}$ See, e.g., Ozimek \& Kilpatrick, supra note 69, at 177 (analyzing an increase in chronic conditions such as obesity and hypertension as potential causes of maternal mortality).

${ }^{78}$ See, e.g., Wagner, Infant Mortality in Europe, supra note 10, at 481 (arguing that the number one lesson the United States can learn from Europe is that infant and maternal mortality are not health problems, but rather social problems that must be solved by providing more social, financial, and educational support to pregnant women and infants); Anna Almendrala, The U.S. Is the Only Developed Nation with a Rising Maternal Mortality Rate, HufFINGTON Post (May 19, 2014), https://www.huffpost.com/entry/us-maternal-mortalityrate n 5340648 [https://perma.cc/H7AW-AHFJ] (reporting author T. R. Reid's conclusion that inadequate access to prenatal health care is to blame for the high MMR in the United States as compared to other "industrialized democracies" offering free or affordable health care). 


\section{Deadly Medicine}

The "biomedical tendency to pathologize otherwise normal bodily processes and states"79 has led to the overuse of medical interventions during labor and birth. These interventions are so common that they are now viewed as part of a "normal" birthing process in the United States. Interventions commonly used during labor and birth include ultrasound, amniocentesis, electronic fetal monitors, intravenous hookups, episiotomy, forceps, vacuum delivery, early induction, and cesarean section as well as restrictions on eating, drinking, movement, and positioning. ${ }^{80}$

Experts have attributed the comparatively high MMR in the United States to excessive and unnecessary use of these interventions. ${ }^{81}$ In particular, almost one-third of babies born in the United States are delivered surgically, which significantly increases the risk of maternal injury and death. ${ }^{82}$ The North American cesarean rate is higher than almost every region in the world, save Latin America and the Caribbean. ${ }^{83}$ WHO has stated that there is no medical justification for a cesarean rate of over ten to fifteen percent, and that higher rates do more harm than good ${ }^{84} \mathrm{~A}$ cesarean is major surgery with all of the attendant physical risks. Women who have this surgery face an increased risk of

\footnotetext{
${ }^{79}$ Diana C. Parry, “We Wanted a Birth Experience, Not a Medical Experience”: Exploring Canadian Women's Use of Midwifery, 29 HeAlth CARE FOR WOMEN INT'L 784, 785 (2008).

${ }^{80}$ See id. at 786; Judith Lothian, Birth Plans: The Good, the Bad, and the Future, 35 J. OBSTETRIC Gynecologic \& NeONATAl Nursing 295, 295-303 (2006); Soc'y of Obstetricians \& Gynaecologists of Can. et al., Joint Policy Statement on Normal Childbirth, 30 J. ObSteTRICS \& GynaeCology CAN. 1163, 1163-65 (2008).
}

${ }^{81}$ See, e.g., Bingham et al., supra note 4, at 191 (arguing that overuse of medical procedures increases severe maternal injuries); Fahmy et al., supra note 4, at 88 (reporting several studies indicating that cesarean sections significantly increase chances of maternal death compared to vaginal birth).

82 See Joyce A. Martin et Al., U.S. Dep’t Health \& Hum. Servs., Births: Final Data for 2018, at 6 (2019), https://www.cdc.gov/nchs/data/nvsr/nvsr68/nvsr68_13-508.pdf [https://perma.cc/DPF5-LRKZ] (reporting a $31.9 \%$ cesarean delivery rate in the United States in 2018).

${ }^{83}$ Ties Boerma et al., Global Epidemiology of Use of and Disparities in Caesarean Sections, 392 LANCET 1341, 1343 (2018).

${ }^{84}$ World Health Org. (WHO), Who Statement on Caesarean Section Rates (2015), https://apps.who.int/iris/bitstream/handle/10665/161442/WHO_RHR_15.02_eng.pdf [https://perma.cc/97GG$8 \mathrm{ZCC}]$. 
illness and death compared to women who give birth vaginally ${ }^{85}$ Several studies reveal that a medically unnecessary cesarean increases the chance of maternal death by at least sixty percent. ${ }^{86}$ Cesareans also increase health risks for future birth. Women with previous cesareans are more likely to have an ectopic pregnancy or develop placenta accreta - serious conditions that can result in massive hemorrhaging. ${ }^{87}$ Studies have shown that babies delivered by cesarean are more likely to suffer physical harm, including respiratory problems and surgical injury. ${ }^{88}$ Despite these risks, the U.S. cesarean rate has alarmingly risen almost $56 \%$ since 1996, with no evidence of improved outcomes. ${ }^{89}$

Other interventions are frequently used despite evidence that they often do not improve, and may even harm, birth outcomes. Physicians induce labor despite evidence that it does not increase the fetus' chance of survival..$^{90}$ They perform routine ultrasounds even though the benefits have never been found to outweigh risks to the fetus and the WHO recommends against regular use. ${ }^{91}$ Importantly, physicians regularly perform episiotomies - surgical incisions intended to widen the vaginal opening for delivery-

\footnotetext{
${ }^{85}$ See Steven L. Clark et al., Maternal Death in the 21st Century: Causes, Prevention, and Relationship to Cesarean Delivery, 199 Am. J. OBSTETRICs \& GyneCology 1, 3 (2008) (finding a maternal mortality rate ten times higher in cesarean birth as compared to vaginal birth in the United States); Shiliang Liu et al., Maternal Mortality and Severe Morbidity Associated with Low-Risk Planned Cesarean Delivery Versus Planned Vaginal Delivery at Term, 176 CANADIAN MED. Ass'N J. 455, 457 (2007) (finding a significantly increased risk of severe postpartum complications among those with planned cesarean birth as compared to vaginal birth); Nat'l Insts. of Health (NIH), CAesarean Childbirth: Consensus Development Conference STATEMENT (1980), https://consensus.nih.gov/1980/1980cesarean027html.htm [https://perma.cc/ABM7WW2K] (stating that a woman who delivers by cesarean section is four times as likely to die in childbirth and twelve times as likely to become ill as a woman who gives birth vaginally).

${ }^{86}$ Fahmy et al., supra note 4, at 88 (reporting several studies indicating that cesarean section significantly increases chances of maternal death compared to vaginal birth).

${ }^{87}$ Michael J. Myers, ACOG's Vaginal Birth After Cesarean Standard: A Market Restraint Without Remedy?, 49 S.D. L. REV. 529, 533 (2003).

${ }^{88}$ See Carol Sakala, Childbirth Connection, Vaginal or Cesarean Birth?: A Systematic Review to Determine What Is at Stake For Mothers AND Babies 3-4 (2006).

${ }^{89}$ Bingham et al., supra note 4, at 191.

${ }^{90}$ Suzanne Hope Suarez, Midwifery Is Not the Practice of Medicine, 5 Yale J.L. \& Feminism 315, 338-42 (1993).

${ }^{91} I d$.
} 
despite a wealth of research rebutting the assumptions underlying the procedure. ${ }^{92}$ This unnecessary surgery, developed in the 1920 s by a doctor intending to save women from the "evils" of labor, can cause significant perineal injury and lasting pain. ${ }^{93}$

Even seemingly "benign" interventions can lead to physical harm. First, there is evidence that interventions often lead to other interventions. ${ }^{94}$ For example, administering the drug Pitocin to induce labor can often lead to a cesarean birth because it causes stronger contractions, increasing the likelihood that a woman will receive pain medication. This makes it harder for her to feel the contractions and deliver vaginally. ${ }^{95}$ Second, even small interventions, such as the routine use of a fetal monitor, can harm women during labor by restricting movement, leading to prolonged labor and intensified pain. ${ }^{96}$

Thus, the country with one of the highest global medical birth intervention rates also has extremely high rates of maternal mortality and morbidity. Importantly, among developed nations, the United States is the only country to eschew midwives for low-risk birth; yet it has one of the highest rates of maternal mortality and is the only country with an increasing MMR. There is strong evidence to suggest that the United States must reexamine its dominant model of childbirth in order to save its birthing women.

\section{Obstetric Violence}

As maternal mortality garners public awareness, the mistreatment of birthing women by medical professionals has also received greater attention. WHO has warned that "disrespectful, abusive, or neglectful treatment" of birthing women in medical facilities is

\footnotetext{
${ }^{92} \mathrm{Id}$.

${ }^{93}$ Elizabeth Kukura, Obstetric Violence, 106 GEO. L.J. 721, 731 (2018) [hereinafter Kukura, Obstetric Violence].

${ }^{94}$ Judith Lothian, Healthy Birth Practice \#4: Avoid Interventions Unless They Are Medically Necessary, $23 \mathrm{~J}$. Perinatal Educ. 94, 96 (2019) (discussing the "cascade" of interventions resulting from the initial use of routine interventions such as restrictions on eating and drinking, intravenous fluids, electronic fetal monitoring, epidural, augmentation of labor, and episiotomy).

${ }^{95}$ Shaw, supra note 55 , at 527.

${ }^{96}$ Lothian, supra note 94, at 199, 201 (discussing the negative effects of movement restriction by electronic fetal monitor and noting "clear and compelling evidence" that this monitoring has no clear benefits); see also Nancy Ehrenreich, The Colonization of the Womb, 43 Duke L.J. 492, 544 (1993) (discussing how the lack of mobility from fetal monitoring and other routine interventions can prolong birth and complicate birth).
} 
a global problem. ${ }^{97}$ Activists in the United States are increasingly referring to this mistreatment as "obstetric violence," a term that originated in Latin America, where some countries have adopted specific prohibitions against such conduct. ${ }^{98}$ Framing mistreatment as obstetric violence challenges the norm that delivering a healthy baby is the only meaningful aspect of birth. It centers discourse on the experience of the laboring woman, recognizing that negative birth experiences can cause significant physical and emotional trauma, regardless of outcome. ${ }^{99}$ As such, the obstetric violence framework encompasses a wide range of mistreatment and harm.

This section provides a detailed explanation of the types of mistreatment and harm suffered by birthing women at the hands of their medical providers. While it is critical to recognize and remedy this harm, framing the problem as "obstetric violence" may limit focus to the actions of individual physicians and foreclose examination of the structural factors that contribute to the mistreatment of birthing women.

\section{Types of Mistreatment}

There is no official definition of obstetric violence. Acknowledging the fluidity of the term, Professor Elizabeth Kukura explains obstetric violence in the United States by classifying relevant conduct of health care providers. She has identified three categories of mistreatment that birthing women suffer: abuse, coercion, and disrespect. ${ }^{100}$

\section{a. Abuse in Childbirth}

Abusive conduct is the most direct and intentional form of mistreatment in the birthing process. Such conduct may include forced surgery (cesareans and episiotomies) and other medical interventions, sexual violation, physical restraint, delay or denial of pain medication, and verbal abuse. ${ }^{101}$ Forced surgery and intervention are shockingly prevalent in North American births. According to a 2014 study, more than half of birth workers in the United States and Canada have witnessed a physician engage in a

\footnotetext{
97 WHO, The Prevention and Elimination of DisRespect and Abuse During Facility-Based Childbirth 1 (2015).

${ }^{98}$ Kukura, Obstetric Violence, supra note 93, at 725.

${ }^{99} \mathrm{Id}$. at 726.

${ }^{100} I d$. at 728 .

${ }^{101} \mathrm{Id}$. at 730 .
} 
procedure against a woman's will, and nearly two-thirds have seen providers "occasionally" or "often" perform procedures without giving a woman a choice or time to consider the procedure. ${ }^{102}$ Such egregious physical violations have caused some women to liken their birth experiences to rape. ${ }^{103}$

\section{b. Coercive Treatment}

Women are both subtly and overtly coerced into accepting a number of interventions during labor. Some of the most egregious coercive tactics include court-ordered interventions and threats of arrest or child apprehension for refusing interventions. ${ }^{104}$ Medical providers may also coerce women to accept a particular intervention by threatening to withhold treatment, manipulating information, making economic threats, or applying emotional pressure. ${ }^{105}$ Another survey conducted in 2014 found that as many as $25 \%$ of new mothers who had induced labors or cesarean deliveries felt pressure to do so, and $63 \%$ of women who had a primary cesarean identified their doctor as the "decisionmaker." 106

Women with previous cesareans and fetuses in the breech position are also coerced to undergo unwanted surgery due to the lack of providers willing to attend vaginal deliveries under these circumstances. Nearly half of U.S. hospitals will not attend vaginal deliveries for women with a prior cesarean ("VBAC") and at least $85 \%$ of U.S. counties lack facilities that offer this option or have providers trained to perform vaginal breech deliveries. ${ }^{107}$ A 2009 study found more than eight hundred hospitals across the U.S. banned VBAC and nearly six hundred additional hospitals were unable to perform

102 Louise Roth et AL., Maternity Support Survey: A Report on the Cross-National SuRVey OF Doulas, Childbirth Educators and Labor and Delivery NuRSES IN THE United STATES AND CANAda 38 (2014).

103 See Jennifer Block, Pushed: The Painful Truth About Childbirth and Modern Maternity Care 146 (2008).

${ }^{104}$ See Farah Diaz-Tello, Invisible Wounds: Obstetric Violence in the United States, 24 REPROD. HEALTH MATTERS 47, 58 (2016).

${ }^{105}$ Kukura, Obstetric Violence, supra note 93, at 750.

${ }^{106}$ Eugene Declercq et al., Major Survey Findings of Listening to Mothers III: Pregnancy and Birth, 23 J. Perinatal Educ. 9, 13 (2014).

${ }^{107}$ Farah Diaz-Tello \& Lynn Paltrow, Birth Justice as Reproductive Justice 4 (May 2012) (unpublished working paper), https://mk0nationaladvoq87fj.kinstacdn.com/wpcontent/uploads/2019/10/Birth20justice202012.pdf [https://perma.cc/BS3H-P37Z]. 
VBACs, because of a lack of providers willing to attend them or strict rules about VBAC that frustrated performance. ${ }^{108}$ Yet the National Institutes of Health (NIH) has recommended VBAC as an appropriate way to lower the national cesarean rate, noting that in many instances VBAC would shorten hospital stay, decrease recovery time, and lower medical costs. ${ }^{109}$

Low-income women and women of color are disproportionately subject to coercive tactics. A national study found that $80 \%$ of court-ordered cesarean sections were performed on women of color. ${ }^{110}$ Twenty-seven percent of court-ordered cesareans were imposed on women who were not native English speakers. ${ }^{111}$ A 2009 study showed that Black women had the highest rate of primary (first birth) cesareans, and that this rate was not attributable to other factors such as education, prenatal care, maternal age, or smoking during pregnancy. ${ }^{112}$ This suggests that the race of the mother has a bearing on the outcome, even in the absence of court-ordered interventions. Socioeconomic status also plays a role: A review of more than four hundred cases of coerced interventions found that most involved low-income women. ${ }^{113}$

\section{c. Disrespect}

Women suffer further mistreatment during birth through disrespectful comments from health care providers. Examples abound of providers ignoring laboring women, accusing them of being selfish or "bad" mothers, and belittling them for their response to

\footnotetext{
${ }^{108}$ See Press Release, Int'l Cesarean Awareness Network, Access to VBAC Shrinking: New Survey Shows Shrinking Options for Women with Prior Cesarean (Feb. 19, 2009), https://icanofjacksonms.blogspot.com/2009/02/access-to-vbac-is-shrinking.html [https://perma.cc/Y3QS5SDA].

${ }^{109}$ Elizabeth Kukura, Choice in Birth: Preserving Access to VBAC, 114 PA. ST. L. REV. 955, 960-61 (2010) [hereinafter Kukura, Choice in Birth].
}

${ }^{110}$ Veronika E. B. Kolder, Janet Gallagher \& Michael T. Parsons, Court-Ordered Obstetrical Interventions, 316 New ENG. J. MeD. 1192, 1192-96 (1987).

${ }^{111} I d$.

${ }^{112}$ Darios Getahun, Racial and Ethnic Disparities in the Trends in Primary Cesarean Delivery Based on Indications, 201 AM. J. OBSTETRICS \& GYNECOLOGY 422 (2009).

${ }^{113}$ Lynn M. Paltrow \& Jeanne Flavin, Arrests of and Forced Interventions on Pregnant Women in the United States, 1973-2005: Implications for Women's Legal Status and Public Health, 38 J. Health Pol. PoL'Y \& L. 299, 299-343 (2013). 
pain. ${ }^{114}$ Such disrespect is particularly harmful when experienced in the emotional and hormonal context of childbirth. ${ }^{115}$

\section{Harm Caused by Obstetric Violence}

Abusive, coercive, and disrespectful treatment of birthing women can cause profound physical, emotional, and even financial damage. The harmful effects of such mistreatment are amplified because they violate the trust women place in medical providers to care for them during this important and emotional life experience. Further, a traumatic birth experience negatively impacts a woman's entire family and may even prevent her from having additional children.

Abusive conduct by medical providers often causes physical harm. Obstetric violence in the form of forced or coerced, unnecessary interventions can cause lasting physical injury to both mother and newborn - and, in the most extreme cases - even maternal death. ${ }^{116}$ Physical restraint and denial of pain medication also cause harm by increasing pain during labor. ${ }^{117}$

Obstetric violence causes significant emotional harm. As many as one-third of surveyed women described their birth experience as traumatic. ${ }^{118}$ Researchers have concluded that $1.5 \%$ to $6 \%$ of women suffer from "birth trauma," a post-traumatic stress disorder that is strongly correlated with high levels of medical intervention. ${ }^{119}$ Such trauma leaves women feeling powerless, alienated, regretful, and sometimes physically or sexually violated. ${ }^{120}$ Birth trauma can have fatal consequences. A British study concluded

\footnotetext{
${ }^{114}$ See Kukura, Obstetric Violence, supra note 93, at 753.

${ }^{115} I d$.

${ }^{116}$ Some advocates classify unnecessary interventions, even when apparently consented to, as obstetric violence. As discussed previously, performing interventions when medically unnecessary, whether or not a woman has meaningfully consented, can cause significant physical injury. See infra Section I.B.2.

${ }^{117}$ Kukura, Obstetric Violence, supra note 93, at 737.

${ }^{118}$ Kristie L. Alcorn et al., A Prospective Longitudinal Study of the Prevalence of Post-Traumatic Stress Disorder Resulting from Childbirth Events, 40 PsYCH. MED. 1849, 1852 (2010).

${ }^{119}$ BLOCK, supra note 103, at 145.

${ }^{120}$ See Kukura, Choice in Birth, supra note 109, at 975-76.
} 
that suicide is the largest cause of death in the year following birth. ${ }^{121}$ Another study found that $9 \%$ of new mothers experience suicidal thoughts. ${ }^{122}$

Obstetric violence also causes financial harm. The most obvious harm is the increased hospital cost from unwanted procedures. However, women may also pay large amounts of money to avoid the specter of coerced intervention and forced surgery. This includes traveling hundreds of miles to receive procedures such as VBAC or to seek out alternative care from midwives. These providers may not be covered by a woman's insurance plan. Furthermore, prior to the implementation of the Affordable Care Actwhich is under threat of repeal - a woman who received a cesarean may have had difficulty obtaining insurance coverage for future births or faced premium increases. ${ }^{123}$

Finally, obstetric violence can interfere with maternal-newborn bonding and disrupt family relations. Forced or coerced cesareans and inductions can delay or prevent crucial early bonding through skin-to-skin contact and breastfeeding. ${ }^{124}$ Emotional and physical trauma caused by obstetric violence can significantly impair a new mother's ability to provide postpartum care. ${ }^{125}$ Some women may blame their partners or abandon plans to conceive additional children as a result of a traumatic birthing experience.

\section{Systemic Causes of Mistreatment}

It is vastly important to recognize the harm caused by obstetric mistreatment, including the role that excessive medical intervention plays in maternal mortality. Unfortunately, "obstetric violence" as a framework places the focus on the individual mother-doctor conflict, foreclosing meaningful systemic scrutiny of the medical model of

\footnotetext{
${ }^{121}$ Mothers \& Babies: Reducing Risk Through Audits \& Confidential EnQuiries Across the UK (MBRRACE-UK), SAVIng Lives, IMPRoving Mothers' CARE: LeSSONS LEARNED TO INFORM MATERNity

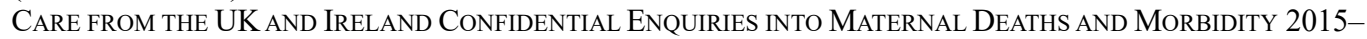
17, at iii (Marian Knight et al. eds., 2019), https://www.npeu.ox.ac.uk/assets/downloads/mbrraceuk/reports/MBRRACE-UK\%20Maternal\%20Report\%202019\%20-\%20WEB\%20VERSION.pdf [https://perma.cc/GLC8-U9MZ].

${ }^{122}$ Louise M. Howard et al., The Prevalence of Suicidal Ideation Identified by the Edinburgh Postnatal Depression Scale in Postpartum Women in Primary Care: Findings from the Respond Trial, 11 BMC PREgnANCY \& ChildBirTh 1, 9 (2011).

${ }^{123}$ Kukura, Choice in Birth, supra note 109, at 986.

${ }^{124}$ See SAKALA, supra note 88 , at 3.

${ }^{125}$ Kukura, Obstetric Violence, supra note 93, at 756.
} 
birth. ${ }^{126}$ Placing rhetorical and legal blame on individual medical providers obscures the many institutional factors that may lead a physician to pressure a woman into accepting a medically unnecessary birth intervention.

As Kukura has acknowledged, obstetric violence cannot be overcome with a singular focus on the bad behavior of individual physicians. ${ }^{127}$ Instead, she identifies a number of institutional factors that contribute to obstetric violence, including economic pressure on medical institutions, the impact of medicalization on doctor-patient relationships, and fear of litigation. ${ }^{128}$ While it is beyond the scope of this Article to examine potential solutions within and related to the medical institution, it is important to recognize that any solution to the problem of birth injury must account for systemic and institutional factors instead of focusing solely on the actions of individuals.

The norm of pregnancy as a condition in need of medical management, coupled with emphasis on a healthy baby as its only important outcome, justifies and obscures the mistreatment of birthing women. We must recognize the profound physical and emotional trauma caused by negative birth experiences and the role that excessive medicalization plays in causing this trauma. It is not enough to ensure that women and infants simply survive birth. Birthing women and newborns, their families, and their communities deserve a meaningful, celebratory and transformative experience.

Thus, what was once a natural process has become a medical condition in need of risk management and intervention. Yet medical intervention has done little to improve health outcomes for birthing women and their newborns. Evidence suggests that it is causing the very harm it seeks to prevent. Infant mortality is astoundingly high. Maternal mortality is significantly high and rising. Women are suffering significant emotional and physical harm at the hands of their medical providers. In sum, the United States has become a dangerous place to give birth.

\section{Midwifery: A Solution in the Shadows}

A shocking number of women are dying, suffering life-threatening complications, and experiencing trauma during birth. Correspondingly, birth in the United States is

\footnotetext{
${ }^{126}$ Because of this individualistic focus and the adversarial nature of this framing, this Article uses the terms "birth injury" or "mistreatment" to describe the harm and actions encompassed by the obstetric violence framework.

${ }^{127}$ Kukura, Obstetric Violence, supra note 93, at 765-66.

${ }^{128}$ Id. at 766 .
} 
overwhelmingly medicalized in comparison to the practices in many other nations with much better birth outcomes. Many of those nations actively promote the use of midwives for the vast majority of births. ${ }^{129}$ Experts across the globe have recognized the importance of state investment in midwifery. ${ }^{130}$ Evidence suggests a powerful correlation between midwifery and improved outcomes for mothers and babies. Further, widespread adoption of midwifery would promote birth as a natural celebratory process rather than a risky medical one, lessening the fear and anxiety that, in extreme cases, cause women to forego reproduction.

Despite the benefits of this alternative model of care, midwifery and out-of-hospital birth are often socially and legally suppressed, discredited or ignored. United States midwives face a number of obstacles to practice, most notably the profit-driven attempts by medical institutions to discredit midwifery and inhibit state licensure and support. The social construction of pregnancy as a high-risk medical condition also inhibits licensing efforts, discourages women from seeking midwifery care, and influences the availability of malpractice insurance and health insurance coverage.

These obstacles have all but constructively eliminated the practice of midwifery in the United States. Only approximately $10 \%$ of all U.S. births are attended by midwives ${ }^{131}$ with less than $2 \%$ of these births occurring outside of hospitals (either in birthing centers or at home). ${ }^{132}$ Medical institutions hold an undeniable monopoly on childbirth, and women are suffering as a result.

This section first provides a detailed explanation of the benefits of midwifery and its ability to reverse the dangerous trend of birth injury. It then describes the many

\footnotetext{
${ }^{129}$ Amnesty Int’L, Deadly Delivery: The Maternal Health Care Crisis in the USA 81 (2010).

${ }^{130}$ See, e.g., Petra ten Hoope-Bender et al., Improvement of Maternal and Newborn Health Through Midwifery, 384 LANCET 1226, 1226 (2014) ("[N]ational investment in midwives and in their work environment, education, regulation, and management ... [is] crucial to the achievement of national and international goals and targets in reproductive, maternal, newborn, and child health.”). See generally Caroline S. E. Homer et al., The Projected Effect of Scaling Up Midwifery, 384 LANCET 1446 (2014); Wim Van Lerberghe et al., Country Experience with Strengthening of Health Systems and Deployment of Midwives in Countries with High Maternal Mortality, 384 LANCET 1215 (2014).
}

${ }^{131}$ MARTIN ET AL., supra note 82, at 29 (finding 9.4\% of U.S. births were attended by Certified Nurse Midwives and $1 \%$ of U.S. births took place in the home in 2018).

132 MacDorman \& Declercq, supra note 56, at 280 (finding 1.61\% of U.S. births occurred outside of the hospital in 2017). 
challenges faced by midwives in the United States and argues for greater state support to overcome these challenges.

\section{A. The Benefits of Midwifery}

Women who birth with midwives have better birth experiences, receive far fewer medical interventions, suffer less birth injury, and pay significantly less than those who birth in the hospital, allowing greater access to prenatal care.

\section{Respectful and Holistic Care}

The midwifery model of care promotes a unified vision of mother and fetus and encourages trusting and comforting relationships between women and their midwives, which leads to better birth experiences. Unlike the medical model of care, midwifery care views birth as a natural event and focuses on engaging women in a celebratory birth process through shared decision making. ${ }^{133}$ Midwives embrace the notion that pain is a normal part of this process and not something to fear. ${ }^{134}$ They aim to provide continuous support with minimal intervention during the birthing process. ${ }^{135}$ Importantly, midwives frame decisions in the context of intertwined needs of a mother and fetus, instead of as a conflict between mother and fetus. ${ }^{136}$

\section{Improved Outcomes}

Those who birth with midwives as their primary providers experience far fewer interventions and improved outcomes. ${ }^{137}$ All European countries with lower infant and maternal mortality rates and cesarean rates than the United States use midwives as the

\footnotetext{
${ }^{133}$ Shaw, supra note 55 , at 530-31.

${ }^{134} \mathrm{Id}$. at 531 .

135 Judith P. Rooks, The Midwifery Model of Care, 44 J. NuRSE-MidwIFERY 370, 372-73 (1999).

${ }^{136}$ Suarez, supra note 90 , at 336.

${ }^{137}$ See Mary J. Renfrew et al., Midwifery and Quality Care: Findings from a New Evidence-Informed Framework for Maternal and Newborn Care, 384 LANCET 1129, 1129-30 (2014) (noting the "growing consensus among public health professionals" that midwifery is essential to maternal care). This consensus is based on randomized controlled trials in high-income settings and practical experience in low-, middle-, and high-income countries that associated the introduction of "educated, trained, motivated, and respected licensed midwives" with a "a rapid and sustained decrease in maternal and newborn mortality, and with an improvement in quality of care." Id.
} 
primary care providers for at least $70 \%$ of births. ${ }^{138}$ For example, like many European countries with state-run health systems, the Netherlands has a tiered system where lowrisk pregnancies are primarily handled by midwives and referred to obstetricians only if complications arise. ${ }^{139}$ As a result, nearly one-third of women in the Netherlands give birth without an obstetrician. ${ }^{140}$ Yet the Netherlands has some of the lowest rates of infant and maternal mortality in the world. ${ }^{141}$ U.S. women who birth with midwives have the same positive experiences as their European counterparts. A three-year study of U.S. birthing centers, where midwives are the predominant care providers, demonstrated significantly better outcomes for both mothers and newborns as compared to national cesarean and morality rates. Of those who had to be transferred to a hospital in labor or after birth, the study revealed no maternal mortality, combined intrapartum (during labor) and neonatal mortality of $0.87 / 1000$, and cesarean rates of $6 \% .{ }^{142}$ In contrast, the national neonatal mortality rate alone was $4.04 / 1000$ births $^{143}$ and the national cesarean rate was $33 \%$ at the time of the study. ${ }^{144}$ A recent study of midwifery in the United States confirmed that, even when controlling for racial disparities in neonatal outcomes, states with higher levels of midwifery integration had "significantly higher rates of spontaneous

\footnotetext{
${ }^{138}$ Wagner, Infant Mortality in Europe, supra note 10, at 481.

139 Therese A. Wiegers et al., Maternity Care in the Netherlands: The Changing Home Birth Rate, 25 BIRTH 190, 192 (1998).

${ }^{140}$ Is There No Place Like Home?, Economist (Mar. 31, 2011), http://www.economist.com/node/18483775 [https://perma.cc/5Q78-AMRE] (reporting nearly one third of Dutch women give birth at home); see also Raymond De Vries et al., The Dutch Obstetrical System: Vanguard of the Future in Maternity Care, in BIRTH MODELS THAT Work 31, 32 (R. Davis-Floyd et al. eds., 2009) (noting 33.4\% of all Dutch births in 2002 were supervised by a midwife).
}

${ }^{141}$ See WHO, Trends in Maternal Mortality, supra note 6, at 102 (finding the Netherlands had MMR of five deaths for every one hundred thousand births in 2017, with only thirteen countries reporting lower numbers); U.N. Inter-Agency Group for Child Mortality Estimation, Mortality Rate, Neonatal (Per 1,000 Live Births), WORLD BANK, http://data.worldbank.org/indicator/SH.DYN.NMRT [https://perma.cc/W26VX4B8] (reporting Netherlands score of three in 2018, with only thirty-one countries reporting lower numbers).

${ }^{142}$ Susan Rutledge Stapleton, Cara Osborne \& Jessica Illuzzi, Outcomes of Care in Birth Centers: Demonstration of a Durable Model, 58 J. Midwifery \& Women’s Health 3, 8-9 (2013).

${ }^{143}$ Sherry L. Murphy et al., U.S. Dep’t of Health \& Hum. Servis., Deaths: Preliminary Data for 2010, at 5 (2012), https://www.cdc.gov/nchs/data/nvsr/nvsr60/nvsr60_04.pdf [https://perma.cc/6S2M-XE27].

144 Joyce A. Martin et al., U.S. Dep’t' of Health \& Hum. Servs., Births: Final Data For 2009, at 2 (2011), https://www.cdc.gov/nchs/data/nvsr/nvsr60/nvsr60_01.pdf [https://perma.cc/P7ZH-YHU6]. 
vaginal delivery, vaginal birth after cesarean, and breastfeeding, and significantly lower rates of cesarean, preterm birth, low birth weight infants, and neonatal death." 145

Additionally, there are many benefits to birthing outside of the hospital. Several European countries actively recommend or support out-of-hospital birth. In the Netherlands, for example, $30 \%$ of births are midwife-assisted home births. ${ }^{146}$ The United Kingdom has issued clinical guidelines recommending that women with low-risk pregnancies be encouraged to birth at home or in a midwife-led birthing center. ${ }^{147}$ Studies of home births have reported positive outcomes. A 2009 study of twenty-eight thousand Canadian home births revealed that outcomes were essentially comparable between planned home births assisted by midwives or physicians and hospital births. ${ }^{148}$ Further, babies born in hospitals were slightly more likely to require resuscitation, oxygen therapy, or hospitalization after birth. ${ }^{149}$ A five-year study of roughly seventeen thousand home births in the United States reported "excellent" outcomes and "very low rates of intervention," including rates substantially lower than the national average in cesareans (5.2\% versus $32.8 \%)$, oxytocin augmentation, and epidural. ${ }^{150}$ The report concluded that such reduced rates "may result in significant cost savings and increased health benefits for low-risk women who give birth outside of the hospital."151

\footnotetext{
${ }^{145}$ Saraswathi Vedam et al., Mapping Integration of Midwives Across the United States: Impact on Access, Equity, and Outcomes, 13 PLOS ONE 1, 1 (2018).
}

${ }^{146}$ Ank de Jonge et al., Perinatal Mortality and Morbidity in a Nationwide Cohort of 529,688 Low-Risk Planned Home and Hospital Births, 116 InT’L J. OBSTETRICS \& GyneCOLOGY 1177, 1178 (2009).

${ }^{147}$ Intrapartum Care for Healthy Women and Babies, Clinical Guideline, NAT'L INST. FOR HEALTH \& CARE EXCELLENCE (Dec. 3, 2014), https://www.nice.org.uk/guidance/cg190/chapter/Recommendations [https://perma.cc/PC2Q-HE3Y].

148 Patricia A. Janssen et al., Outcomes of Planned Home Birth with Registered Midwife Versus Planned Hospital Birth with Midwife or Physician, 181 CANADIAn MED. Ass'N J. 377, 377-83 (2009) (noting the study limitation of self-selection within the population of women choosing home birth).

${ }^{149} I d$.

${ }^{150}$ Melissa Cheyney et al., Outcomes of Care for 16,924 Planned Home Births in the United States: The Midwives Alliance of North America Statistics Project, 2004 to 2009, 59 J. Midwifery \& Women's Health 17, 17-27 (2014) (noting the study limitation of self-selection within the population of women choosing home birth).

${ }^{151} I d$. 


\section{Lower Cost and Greater Accessibility}

Midwifery care is more affordable and accessible than traditional medical care. Midwifery services typically cost between $\$ 3,000$ and $\$ 9,000 .{ }^{152}$ This is a significant savings compared to the roughly $\$ 30,000$ that hospitals charge for a vaginal birth. ${ }^{153}$ Midwifery further lowers health care costs by reducing interventions such as ultrasounds and cesareans, which cost approximately $40 \%$ more than vaginal births. ${ }^{154}$ Additionally, midwives offer care in rural areas where women may face a lack of providers able or willing to attend births for low-income women. In some rural areas, midwives provide more care to women on Medicaid than obstetricians. ${ }^{155}$ The Institute of Medicine published a 2010 report which found that midwives improved primary health care services for women in rural and inner-city areas, and which recommended that midwives be given more responsibility for providing women's health care. ${ }^{156}$

Numerous studies and decades of international practice support the benefits of midwife-attended birth and suggest that greater adoption of midwifery and the midwifery model of care would vastly improve childbirth in the United States. To truly reverse our dangerous mortality trends, midwifery must be brought from the shadows, and birth without intervention must be normalized.

\section{B. Institutional Struggles}

As birth becomes increasingly dangerous under the prevailing medical model, it is imperative that we analyze and address the many structural factors preventing the widespread adoption of midwifery. There has been significant renewed interest in non-

\footnotetext{
${ }^{152}$ Amanda Krupa, This Is How Much It Costs to Have a Home Birth in America, PARENTs (May 7, 2020), https://www.parents.com/pregnancy/giving-birth/home/home-birth-cost-in-america/ [https://perma.cc/QXC2LNRE].

${ }^{153}$ Elisabeth Rosenthal, American Way of Birth, Costliest in the World, N.Y. Times (June 30, 2013), https://www.nytimes.com/2013/07/01/health/american-way-of-birth-costliest-in-the-world.html [https://perma.cc/JB5Y-CDAK].

${ }^{154} I d$. (finding the average cost of cesarean was $\$ 50,000$, compared to $\$ 30,000$ for vaginal birth).

${ }^{155}$ See Kevin Grumbach et al., Who Is Caring for the Underserved? A Comparison of Primary Care Physicians and Non-Physician Clinicians in California and Washington, 31 AnNALs FAM. MED. 97, 97-104 (2003).

156 COMM. ON THE ROBERT WOOD JOHNSON Found. InITIATIVE ON THE FUtURE OF NURSING, AT THE INST. OF Med., The Future of Nursing: Leading Change, Advocating Health (2011).
} 
medical birth in the United States over the last two decades, and when people choose non-medical birth, they often choose midwives to assist them. ${ }^{157}$ Yet, despite increased demand for services, out-of-hospital midwifery in the United States is almost nonexistent. Midwives face numerous barriers to practice, including difficulty obtaining supplies, assistance, and malpractice insurance, difficulties obtaining clients due to lack of health insurance coverage, and even threat of criminal prosecution. This section examines the primary factors contributing to these problems: uncertain legal status within the midwife's state of practice and monopolistic practices by medical institutions.

\section{Uncertain Legal Status}

Midwives in the United States are predominantly trained and certified professionals. They work in a variety of settings, including hospitals, birthing centers, and homes. The three professionally certified types of midwives are Certified Professional Midwives (CPM), Certified Nurse-Midwives (CNM), and Certified Midwives (CM). ${ }^{158} \mathrm{CNMs}$ are nurses who have also completed a graduate midwifery program $^{159}$ and work primarily in hospitals. ${ }^{160} \mathrm{CMs}$ are non-nurses who complete the same graduate program. ${ }^{161} \mathrm{CPMs}$ are certified midwives who have either apprenticed with a qualified midwife and passed an evaluation process or graduated from a midwifery program or school. ${ }^{162}$ Certification and training are provided by well-established organizations, such as The North American Registry of Midwives (NARM) and the Midwives' Alliance of North America (MANA). ${ }^{163}$ There are two types of uncertified midwives practicing in the United States.

\footnotetext{
${ }^{157}$ A government study indicated a dramatic 77\% increase in home births from 2004 to 2017 and a doubling of birth center births during that same time period. Midwives attended over $80 \%$ of these planned home births and over $93 \%$ of birth center births. MacDorman \& Declercq, supra note 56, at 280, 283.
}

${ }^{158}$ What Is a Midwife?, GRADUATENURSINGEDU.ORG, https://www.graduatenursingedu.org/careers/certifiednurse-midwife/what-is-a-midwife/ [https://perma.cc/SF5Y-KNA2].

${ }^{159} \mathrm{Id}$

160 See Am. Coll. of Nurse-Midwives, Essential Facts About Midwives (May 2019), https://www.midwife.org/acnm/files/cclibraryfiles/filename/000000007531/EssentialFactsAboutMidwivesUPDATED.pdf [https://perma.cc/U8YY-JQTM] (finding that 94.1\% of CNM/CM-attended births occurred in hospitals).

${ }^{161} I d$

${ }^{162} I d$

${ }^{163}$ Midwives All. OF N. Am., https://mana.org [https://perma.cc/NMY8-R966]; N. AM. ReGISTRY OF MiDWIVES, http://narm.org [https://perma.cc/A64B-LPHB]. 
Direct Entry Midwives (DEMs) provide care in out-of-hospital settings, such as homes and birth centers, primarily through self-employment. ${ }^{164}$ There is no official certification available for DEMs, though CMs, CPMs, and CNMs who work outside of hospitals are also considered DEMs. ${ }^{165}$ Uncertified midwives with less formal education also continue to operate in the United States, embracing the historical practice of learning midwifery through passed-down knowledge and firsthand experience. ${ }^{166}$ These midwives are known by a variety of names, including lay midwife, traditional midwife, and community midwife. ${ }^{167}$

Each state has its own certification and licensing requirements for the various types of midwives. All fifty states license and/or regulate CNMs. ${ }^{168}$ However, DEMs, who work outside of the hospital in homes or birth centers, receive varying degrees of state recognition. ${ }^{169}$ Only slightly more than half of U.S. states regulate CPMs, primarily through licensing. ${ }^{170}$ No state licenses uncertified midwives. In some cases, DEMs are outright banned from practicing. DEMs are essentially illegal in Georgia, Illinois, North

\footnotetext{
${ }^{164}$ GradUATENuRSINGEDU.orG, supra note 158.

165 Id.

${ }^{166}$ Id.; see also FRASER, supra note 26, at 26.

${ }^{167}$ Helen Varney \& Joyce Beebe Thompson, A History of Midwifery in the United States: The Midwife SAID FEAR Not 126 (2016). These names may also be used to refer to any non-nurse midwife, including CMs and CPMs. Id. at 83.
}

${ }^{168}$ Why AMCB Certification?, AM. MiDwIFERY CERTIFICATION BD., https://www.amcbmidwife.org/amcbcertification/why-amcb-certification- [https://perma.cc/7VZJ-77K7].

169 This Article is primarily concerned with the benefits of midwifery in out-of-hospital settings, and is thus focused on Direct Entry Midwives, rather than nurse midwives (CMs and CNMs), most of whom work in hospitals. See AM. Coll. Of NurSE-Midwives, supra note 160 (finding that $94.1 \%$ of CNM/CM-attended births occurred in hospitals). While the presence of midwives at hospital births is undoubtedly beneficial, nurse-midwives already receive some level of state support through licensing and do not face the obstacles outlined in this Part to the same degree as DEMs, because they work within the medical model of birth. The term "midwife" is used throughout this Article primarily in reference to DEMs.

${ }^{170}$ N. Am. Registry of Midwives (NARM), Direct Entry Midwifery State-By-State Legal Status (May 5, 2019), http://narm.org/pdffiles/Statechart.pdf [https://perma.cc/VW5Y-JUYV]. After the publication of this document, midwifery became legal in Kentucky when they enacted a law to license CPMs. Chelsea Washington, A New Law Recognizes Midwives, SPeCtrum News 1 (July 12, 2019), https://spectrumnews1.com/ky/lexington/news/2019/07/12/professional-certified-midwives[https://perma.cc/F3GW-BHHT]. 
Carolina, and Washington, D.C. ${ }^{171}$ The remaining states have no formal regulation of DEMs. ${ }^{172}$ In some states with no regulation, such as Nevada, DEMs practice openly and are generally treated with respect by government. ${ }^{173}$ In others, the legal status of DEMs is entirely unclear. ${ }^{174}$

Midwives have good reason to be concerned about unclear legal status as well as outright criminalization. They are being prosecuted for poor birth outcomes. There are no recent statistics on the number of midwife prosecutions, but data from 2002 indicates that approximately fifty midwives nationwide have been sentenced to prison for fetal demise or for practicing without a license. ${ }^{175}$ There have been several high-profile prosecutions since that time. ${ }^{176}$ While some midwives practice openly in defiance of a state ban, ${ }^{177}$ the majority are likely fearful of such prosecutions even in states that have no formal laws regarding midwifery, leaving these cases open to judicial interpretation.

${ }^{171}$ NARM, supra note 170.

${ }^{172}$ Id. (listing Connecticut, Iowa, Kansas, Massachusetts, Mississippi, Nebraska, Nevada, North Dakota, Ohio, Oklahoma, Pennsylvania, and West Virginia as "Inference/unregulated").

173 Jessica Brown, The Fight for Birth: The Economic Competition that Determines Birth Options in the United States, 52 U.S.F. L. REV. 1, 25 (2018).

${ }^{174}$ See, e.g., Linda Levinson, Comment, Solving The Modern "Midwife Problem": The Case For Non-Nurse Midwifery Legislation in Pennsylvania, 91 TEMP. L. REV. 139, 154-57 (2018) (describing the "confusion surrounding the legal status of home birth and non-nurse midwives in Pennsylvania"); Emily Le Coz et al., Ohio Among More than a Dozen States that Don't Regulate Non-Nurse Midwives, The Columbus Dispatch (Nov. 26, 2018), https://www.dispatch.com/news/20181126/ohio-among-more-than-dozen-states-that-dontregulate-non-nurse-midwives/1 [https://perma.cc/2CU7-N9H5] (discussing the "Wild West landscape" of Ohio and other states where DEMs are unregulated).

175 Martha Mendoza, Midwives Give Birth to Lawsuits, Criminal Charges, L.A. Times

(Nov. 24, 2002), http://articles.latimes.com/2002/nov/24/news/admn-midwives24 [https://perma.cc/C7X8SABP].

${ }^{176}$ See Jennifer Block, The Criminalization of the American Midwife, LONGREADS (Mar. 2020), https://longreads.com/2020/03/10/criminalization-of-the-american-midwife/ [https://perma.cc/L34G-77HL]; Libby Copeland, When a Home Birth Ends in Tragedy, Can the Midwife Go to Jail?, SLATE (May 9, 2011), https://slate.com/human-interest/2011/05/midwife-karen-carr-s-guilty-plea-when-home-births-go-wrong-aremidwives-criminally-liable.html [https://perma.cc/FXC6-LP4K]; Adam Liptak, Prosecution of Midwife Casts Light on Home Births, N.Y. Times (Apr. 3, 2006), http://www.nytimes.com/2006/04/03/us/03midwife.html [https://perma.cc/N4L3-7W2C].

177 See Georgia Midwife Sues to Continue Speaking Truthfully About Her Profession, PAC. Legal Found., https://pacificlegal.org/case/debbie-pulley-v-janice-izlar [https://perma.cc/XYU6-GFG8] (reporting on a Georgia midwife who visibly practiced for years despite illegality). 
Without the clear protection and support of the state, midwives are effectively driven underground and left to fend for themselves. It is undoubtedly significantly harder for them to obtain clients or procure the necessary supplies and support of backup hospitals and physicians when out-of-hospital midwifery is viewed as illegal. Further, midwives suffer economic harm in part because of their uncertain legal status. They face difficulties obtaining malpractice insurance and are thus extremely vulnerable to threat of lawsuit. ${ }^{178}$ Some sort of formal recognition of midwifery by regulatory scheme in all states would likely help malpractice insurers feel more confident in covering midwifery services. There is certainly little to no chance of obtaining malpractice insurance in a state where direct-entry midwifery is illegal. Midwives also find it difficult to obtain clients because health insurance often does not cover midwifery services. ${ }^{179}$ Almost half of U.S. births are covered by Medicaid, ${ }^{180}$ yet only about fourteen states allow reimbursement of direct entry midwives. ${ }^{181}$ Further, only thirty-three states have laws requiring private insurers to cover midwifery services. ${ }^{182}$ The Affordable Care Act now prohibits private insurers from discriminating against providers acting within the scope of their licenses in plan participation and coverage. ${ }^{183}$ This may help to expand coverage of midwifery services, but only to those midwives licensed by the state. ${ }^{184}$

\footnotetext{
178 See Deborah A. Sullivan \& Rose Weitz, Labor Pains 147 (1988) (discussing insurance carriers' decision to stop offering malpractice insurance to midwives at a lower premium, effectively making insurance unavailable to midwives by forcing them to pay obstetrician rates despite a much lower risk factor).

${ }^{179}$ See AMNESTY INT'L, supra note 129, at 81 (noting that “[m]idwifery care options are frequently not reimbursed by public or private insurance"); DiANA KORTE \& ROBERTA SCAER, A GOOD BirTH, A SAFE BIRTH 47, 48 (3d rev. ed. 1992) (finding health insurance companies in most states do not cover home birth).
}

${ }^{180}$ MEDICAID \& CHIP PAYMENT \& ACCESS COMM'N (MACPAC), FACT SHEET: MEDICAID's ROLE IN
FINANCING MATERNITY CARE 1 (Jan. 2020), https://www.macpac.gov/wp-
content/uploads/2020/01/Medicaid\%E2\%80\%99s-Role-in-Financing-Maternity-Care.pdf
[https://perma.cc/6JZ7-ZBGW].

${ }^{181}$ NARM, supra note 170.

182 See Elizabeth Rosenthal, Getting Insurance to Pay for Midwives, N.Y. TimEs (July 3, 2013), http://well.blogs.nytimes.com/2013/07/03/getting-insurance-to-pay-for-midwives [https://perma.cc/MKS8JDWF].

${ }^{183}$ Caitlin McCartney, The Patient Protection and Affordable Care Act and Choice in Childbirth: How the ACA's Nondiscrimination Provisions May Change the Legal Landscape of Childbirth, 24 AM. U. J. GENDER SOC. POL'Y \& L. 337, 355 (2016) (discussing the ACA's inclusion of midwifery services in health care coverage).

${ }^{184}$ Id. at $355-57$. 
Thus, at a minimum, the state must grant clear legal status to midwives. Without legal recognition, midwifery will remain largely unsupported, underused, and underground.

\section{Medical Monopoly}

The overwhelming dominance of medical birth in the United States has given hospitals a powerful profit-driven incentive to suppress midwifery. The normalization of medical birth and risky pregnancy both motivates and allows medical professionals and their advocates to exert significant influence over birthing legislation at all levels of government. The result is a maternity system in which responsibility for birth is relegated to the marketplace, yet hospitals hold a clear monopoly.

Economic competition is at least partly to blame for physician and hospital efforts to discredit and suppress the work of midwives. Professor Stacey Tovino provides several historical examples showing that the medical establishment increased efforts to terminate midwifery practices only after it became apparent that the two were competing for patients. ${ }^{185}$ For example, some physicians in Alabama were generally supportive of midwives, possibly because midwifery patients were mostly poor Black women who could not afford to pay a higher physician rate. ${ }^{186}$ However, when the state started issuing permits for midwives to attend the deliveries of patients at a public health clinic, midwifery fees increased and became easier to collect through the state. ${ }^{187}$ The medical establishment then increased its efforts to terminate midwifery practices, lobbying the Alabama legislature to eventually pass a 1976 law that essentially ended the practice of direct-entry midwifery. ${ }^{188}$

It is not just individual physicians and institutions lobbying to suppress midwifery. Powerful professional organizations exert significant influence on birthing regulation as well. The American College of Obstetricians and Gynecologists (ACOG) has a federal political action committee (PAC) as well as lobbyist positions in all fifty states. ${ }^{189}$ The

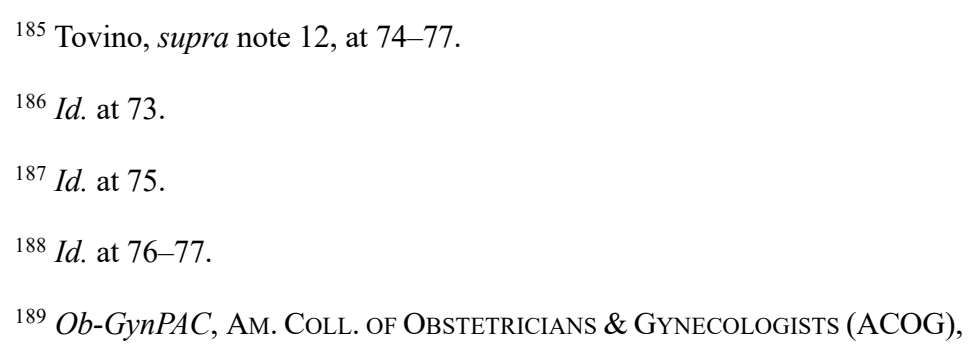


American Medical Association (AMA), another politically and socially powerful organization, has also significantly influenced birthing legislation. The AMA has a long history of opposing government involvement in birth care. In 1921, Congress passed the Sheppard-Towner Act, one of the few pieces of federal legislation aimed at addressing maternal and infant mortality. ${ }^{190}$ The Act, considered the government's first foray into social security legislation, provided funding for a number of initiatives, including a multistate program that employed nurses to educate midwives in poor and rural areas. ${ }^{191}$ Under pressure from the AMA, Congress explicitly did not allocate funds for medical care because the AMA viewed this as socialist encroachment on their professional autonomy. ${ }^{192}$ The AMA was also largely influential in preventing the renewal of the Act eight years later, ${ }^{193}$ despite the Act's apparent success in having enabled the establishment of thousands of prenatal clinics, millions of home visits by public health nurses, and several state programs to license and train midwives. ${ }^{194}$ In more recent times, the AMA has adamantly opposed home birth. In 2008, they reportedly adopted a resolution to introduce legislation outlawing home birth, ${ }^{195}$ and considered a motion to

https://www.acog.org/en/Advocacy/Ob-GynPAC [https://perma.cc/L299-6S92]; Connect with ACOG's State Advocacy Leaders, ACOG, https://www.acog.org/advocacy/get-involved/connect-with-acogs-state-advocacyleaders [https://perma.cc/HL5A-96FS].

${ }^{190}$ Sheppard-Towner Act of 1921, ch. 135, 42 Stat. 224, repealed by Act of Jan. 22, 1927, ch. 53, § 2, 44 Stat. 1024.

${ }^{191}$ FRASER, supra note 26, at 34.

192 Warren G. Harding - Key Events, UVA MILLER CTR., https://millercenter.org/president/warren-gharding/key-events [https://perma.cc/5JPZ-VFVK]; Katherine Madgett, Sheppard-Towner Maternity and Infancy Protection Act (1921), The EMBryo ProjeCt ENCYClopedia (May 18, 2017), https://embryo.asu.edu/pages/sheppard-towner-maternity-and-infancy-protection-act-1921 [https://perma.cc/2P6X-DTKB].

${ }^{193}$ Madgett, supra note 192.

${ }^{194} I d$. However, some have argued that the Sheppard-Towner Act was ultimately responsible for a decline in midwifery as the medical professionals responsible for educating midwives established connections within the community and promoted the medical model of birth. See Jillian M. Duquaine-Watson, Sheppard-Towner Maternity and Infancy Protection Act of 1921, in THE SOCIAL History OF THE AMERICAN FAMILY: AN ENCYCLOPEDIA 1182 (Marilyn J. Coleman \& Lawrence H. Ganong eds., 2014); Liana Aghajanian, Los Angeles Midwives Aim to End Racial Disparities at Birth, Al JAZEERA Am. (Sept. 5, 2015), $\mathrm{http} / / /$ america.aljazeera.com/articles/2015/9/5/to-los-angeles-midwives-racial-disparities-birth.html [https://perma.cc/9TDB-F5FJ] (noting in particular the impact of the Act on Black midwives).

${ }^{195}$ Amie Newman, Bad Medicine: AMA Seeks to Outlaw Home Births, Rewire News GrP. (June 16, 2008), https://rewire.news/article/2008/06/16/bad-medicine-ama-seeks-to-outlaw-home-births [https://perma.cc/BWN3-ERAP]. 
censure Ricki Lake, a celebrity actress and talk show host, for promoting home birth in her popular documentary, The Business of Being Born. ${ }^{196}$ Thus, by overemphasizing the pathological potential of pregnancy and asserting rights to market autonomy, the medical lobby has spent one hundred years successfully convincing legislators that physician treatment is required for the safety of the mother and fetus. ${ }^{197}$

Even in states that offer comprehensive midwife licensing and regulation, the medical industry can adversely affect the availability of licenses or can work to impose unnecessary restrictions on midwifery. Midwives may face difficulty obtaining a license due to the composition of state licensing boards. In some states, the agencies that regulate or license midwifery are controlled by professional organizations comprised primarily of physicians. ${ }^{198}$ This arguably creates a conflict of interest, since the very people in charge of licensing and regulating midwives are in direct competition with midwives for patients. For example, in Georgia, the Board of Nursing took over midwifery licensing from the state health department in 2015 and promptly required midwives to obtain a nursing degree and become CNMs in order to practice. ${ }^{199}$ In 2019, Debbie Pulley, a CPM with over twenty years of experience and a board member of the qualification organization NARM, sued the Georgia Board of Nursing for violation of her free speech rights after the Board sent cease and desist letters forbidding her from identifying herself as a "midwife" in any form and threatening her with a \$500 fine for each violation. ${ }^{200}$ Such outcomes are unsurprising from a Board whose members are almost entirely nurses and whose advisory committee is largely comprised of medical professionals. ${ }^{201}$

Advisory committees of medical professionals also have significant influence over state regulations that govern access to midwifery care. For example, Arizona's Midwifery

${ }^{196}$ Elizabeth Mitchell Armstrong, Home Birth Matters—For All Women, 19 J. Perinatal EduC. 8 , 8 (2010).

${ }^{197}$ Suarez, supra note 90 , at 320 .

198 See Barry R. Furrow et AL., The Law OF HealthCARE Organization AND FinanCe 98 (6th ed. 2008) (noting that members of the licensed profession typically dominate state licensing boards, creating a conflict of interest).

${ }^{199}$ PAC. Legal Found., supra note 177.

${ }^{200} I d$.

${ }^{201}$ Board Members and Staff, GA. SEC'Y OF STATE, https://sos.ga.gov/index.php/licensing/plb/45/board_members_and_staff [https://perma.cc/EX4E-A3X2] (showing ten of eleven sitting board members are RNs or LPNs); $\bar{A} d$ visory Committees, GA. SEC'Y OF STATE, https://sos.ga.gov/index.php/licensing/plb/45/advisory_committees [https://perma.cc/WF4J-EV5G]. 
Advisory Committee is comprised of midwives but is also required to include a licensed physician and nurse-midwife. ${ }^{202}$ As a result, the state health agency adopted several rules that unduly restrict access to care. Women are allowed to attempt VBAC at home, but only if they live within twenty-five miles of a hospital, significantly impacting women in rural areas. ${ }^{203}$ Further, Arizona rules require labor to stay within ACOG's guidelines for active labor, which are partly to blame for the frequent usage of interventions in hospital settings. ${ }^{204}$ Arizona regulations also require midwives to obtain physician approval to procure medications, a restriction that many other states do not impose. ${ }^{205}$

Midwives are further harmed when individual physicians refuse cooperation efforts. Midwives require the availability of a backing physician and hospital in case a woman needs medical care during birth. ${ }^{206}$ If no physicians agree to do this, midwives either cannot operate at all or must attempt to convince clients to handle emergency care on their own. Women are significantly disadvantaged if midwives and physicians cannot provide continuity of care during a medical emergency, including a smooth hospital transition plan that involves communication between midwives and physicians. Many women are unlikely to consider out-of-hospital birth, or even prenatal midwifery care, without a clear plan to involve a physician should it become medically necessary.

Legislative and regulatory opposition to midwifery is not entirely motivated by profit-driven capture or reluctance to interfere with private market transactions. The social construction of pregnancy as medically risky motivates advocates, medical professionals, and legislators to perpetuate the medical model of childbirth. This becomes a vicious cycle of sorts. State promotion of midwifery and non-hospital birth is essential to normalize birth without intervention, yet the state is constrained from acting by the current discourse of medical birth that it must seek to change. Instead, through its refusal to legally recognize midwifery or its adoption of laws that reaffirm pregnancy as risky, the state operates to maintain the status quo.

\footnotetext{
${ }^{202}$ See Dingott, supra note 7, at 456.

${ }^{203}$ Id. at 457.

${ }^{204} I d$. at 458 .

${ }^{205}$ Id. at 459 .

${ }^{206}$ See Am. Coll. of Nurse-Midwives, Standards for the Practice of Midwifery, https://www.midwife.org/acnm/files/ACNMLibraryData/UPLOADFILENAME/000000000051/Standards_fo r_Practice_of_Midwifery_Sept_2011.pdf [https://perma.cc/A7KZ-ADVM] (requiring midwives to "[d]emonstrate a safe mechanism for obtaining medical consultation, collaboration, and referral").
} 
To be sure, some pregnancies are higher risk and require a greater degree of medical care. In these situations, it is best for women to use physicians as their primary care providers and/or give birth in a hospital. Midwives certainly recognize that midwifery is not appropriate for all patients. Prominent certification organizations require CPMs to adopt practice guidelines outlining the medical conditions under which a patient will be accepted, the outcomes necessitating transfer of patient care to a physician or hospital, and the procedure for consultation or transfer of care. ${ }^{207}$ Additionally, several states require consultation or transfer of care when a client experiences medical complications during pregnancy or birth. ${ }^{208}$ Therefore, it is certainly possible for the state to address legitimate safety concerns regarding midwifery while still actively promoting midwifery as the best option for low-risk birth, and while encouraging cooperation between physicians and midwives.

Thus, medical consumerism, market competition, and powerful social and cultural norms combine to create an environment in which physicians are incentivized to coerce women into unnecessary procedures while simultaneously suppressing the availability of less invasive birthing options, such as midwifery. Indeed,

[I]n just half a century, allopathic physicians in the U.S. have enticed 99 percent of us into their places of business (hospitals) for childbirth, forced on us a medical model of birth . . . raised the price of services . . . and lobbied state legislatures for laws that would require us to submit to their exclusive control during pregnancy and childbirth. ${ }^{209}$

Midwives are significantly disadvantaged in such a system. At best, they have to compete for patients with large medical institutions that have the resources and influence necessary to mount campaigns to discredit and suppress their work. At worst, they are outlawed from operating within a state and must face sanctions, including imprisonment, if they continue to practice without a license.

Midwifery and out-of-hospital birth offer significant hope for improving birth experiences. Yet midwifery, currently utilized by only a tiny percentage of U.S. women,

\footnotetext{
${ }^{207}$ See, e.g., CPM Practice Guidelines, N. AM. REGISTRY OF MiDwIVES (NARM), https://narm.org/faq/cpmpractice-guidelines [https://perma.cc/D9EF-ZC28].

${ }^{208}$ See, e.g., Dingott, supra note 7, at 458-59 (analyzing Arizona regulations that very specifically outline the conditions that require midwives to transfer care or consult with a physician); WASH. REV. CODE $§ 18.50 .108$ (1981) (requiring midwives maintain a written plan for consultation and transfer of care to a physician).

${ }^{209}$ Suarez, supra note 90 , at 315 .
} 
is almost entirely unsupported by the state. The remainder of this Article seeks largely to examine the reasons for this lack of support and to offer an alternative framework for imagining meaningful state responsibility for birth.

\section{The Unresponsive State}

There should be little doubt that the state is obligated to mitigate the increasing danger to its birthing women and to societal reproduction as a whole. Yet the state has done very little to even examine the causes of birth injury, much less address them through any type of meaningful legislation or regulation. Despite three decades of alarming MMR increase, the state seems only to be in the "information gathering" phase of addressing the problem. Seemingly few individual state governments have taken significant action to lower MMR. ${ }^{210}$ Many more have inadequate procedures for analyzing maternal deaths or do not collect information at all. ${ }^{211}$ Federal government response has been limited and focused on data collection. ${ }^{212}$ The state has done nothing to address the growing problem of obstetric mistreatment.

Further, state response to birth injury has either rejected or entirely ignored the harm caused by medicalization and the numerous benefits of midwifery. This is certainly due in part to the significant influence medical professionals exert through participation in state Maternal Mortality Review Committees (MMRC). MMRCs conduct in-depth reviews of maternal deaths to gain a greater understanding of the cause. ${ }^{213}$ In some states,

\footnotetext{
${ }^{210}$ See Gaby Galvin, How America Is Combatting Maternal Mortality, U.S. News (June 19, 2019), https://www.usnews.com/news/health-news/articles/2019-06-19/whats-being-done-to-fight-maternalmortality-in-america (reporting difficulties in establishing state policy without standardized data collection and highlighting only thirteen states with perinatal quality collaboratives that "may develop initiatives based on mortality review board findings" as only example of state action); Renee Montagne, To Keep Women from Dying in Childbirth, Look to California, NPR (July 29, 2018),

https://www.npr.org/2018/07/29/632702896/to-keep-women-from-dying-in-childbirth-look-to-california [https://perma.cc/AZ3K-S2UW] (reporting that California is "leading the charge" in its efforts to combat maternal mortality).
}

${ }^{211}$ Nina Martin, "Landmark” Maternal Health Legislation Clears Major Hurdle, ProPuBLICA (Dec. 12, 2018), https://www.propublica.org/article/landmark-maternal-health-legislation-clears-major-hurdle [https://perma.cc/GSR8-LVAD].

${ }^{212} I d$.

${ }^{213}$ CDC, State Maternal Mortality Review: Accomplishments of Nine States 1 (Stephen J. Bacak et al. eds., 2006), http://www.amchp.org/Calendar/Webinars/Womens-Health-Info-Series/Documents/StrII.pdf [https://perma.cc/DB4V-ZFA6]. 
MMRCs have existed for over eighty years. ${ }^{214}$ Historically they consisted of one or more physicians examining medical cause of death, but some evolved to include representatives of a variety of social service professions in an effort to examine the wider social causes of mortality. ${ }^{215}$ In 2018, only thirty-six states had such committees, and some of these were severely underfunded or published irregular or low-quality findings. ${ }^{216}$

In response to growing pressure to address maternal mortality, Congress passed the federal Preventing Maternal Deaths Act in late 2018. ${ }^{217}$ The Act provides funding to establish MMRCs in all fifty states under a set of uniform guidelines in an effort to improve data collection. ${ }^{218}$ Unfortunately, the Act does nothing to address the conflict of interest inherent in allowing medical professionals to dominate MMRC membership. An in-depth USA Today study of MMRCs found that "panels in three states are partly or fully controlled by private medical associations and lobbying groups that represent the interests of doctors or hospitals. In all states, panels are stocked with doctors, nurses, and hospital officials - the people involved in the care that would be scrutinized." ${ }^{219}$ For a variety of reasons, including profit motivation, physicians and hospital representatives are unlikely to seriously examine the role medical intervention plays in maternal mortality. And there is good reason to be concerned that members of the medical industry will choose to place the blame elsewhere in examining maternal deaths. The USA Today study found that "at least 30 states have avoided scrutinizing medical care provided to mothers who died, or they haven't been studying deaths at all.",220 Many states emphasized individual lifestyle choices such as smoking or "getting too fat" or larger

\footnotetext{
${ }^{214} I d$.

${ }^{215} I d$.

${ }^{216}$ Martin, supra note 211; Laura Ungar, What States Aren't Doing to Save New Mothers' Lives, USA TodAY (Nov. 14, 2019), https://www.usatoday.com/in-depth/news/investigations/deadlydeliveries/2018/09/19/maternal-death-rate-state-medical-deadly-deliveries/547050002/ [https://perma.cc/WVV3-Y2KN].

${ }^{217}$ Preventing Maternal Deaths Act of 2018, Pub. L. No. 115-344, 132 Stat. 5047 (codified as amended at 42 U.S.C. $\S 247 b-12)$.

${ }^{218} I d$.

${ }^{219}$ Ungar, supra note 216.

${ }^{220} \mathrm{Id}$.
} 
social and environmental issues such as opioid abuse, motor vehicle crashes, and lack of smoke detectors instead of scrutinizing the quality of medical care. ${ }^{221}$

Efforts to require MMRCs to conduct a more thorough examination of medical care were met with resistance from state legislators concerned about intruding on the doctorpatient relationship. ${ }^{22}$ This intrusion may have been a concern of federal legislators as well. The version of the Act first introduced in the House had several specific requirements regarding the composition of MMRCs, including the requirement of midwife participation. ${ }^{223}$ Along with physicians and nurses, state health workers, social workers, and advocates of racial groups most affected by maternal mortality, the Act required committees to contain both CNMs and CMs ${ }^{224}$ Unfortunately, after years of stalling in House committee, the final version of the Act passed with only the following requirement regarding MMRC composition, which makes no specific mention of midwifery:

[MMRCs must] include multidisciplinary and diverse membership that represents a variety of clinical specialties, State, tribal, or local public health officials, epidemiologists, statisticians, community organizations, geographic regions within the area covered by such committee, and individuals or organizations that represent the populations in the area covered by such committee that are most affected by pregnancy-related deaths or pregnancy-associated deaths and lack of access to maternal health care services. ${ }^{225}$

Failing to mandate the inclusion of midwives in MMRCs ensures that the medical model of birth will continue to dominate analysis and recommendations regarding maternal mortality. Congress missed an opportunity to address the conflict of interest that will very likely prevent meaningful change to medical procedures, such as those enacted

\footnotetext{
${ }^{221} I d$.

${ }^{222}$ See id. (reporting that "[s]everal lawmakers said a more aggressive death review panel would meddle too much in how doctors treat patients").

${ }^{223}$ Preventing Maternal Deaths Act of 2018, H.R. 1318 (1st Sess. 2017) (as introduced in House).

${ }^{224} I d$

${ }^{225}$ Preventing Maternal Deaths Act, 42 U.S.C. $\$ 247 b-12$ (2018).
} 
in California to prevent hemorrhaging. ${ }^{226}$ More importantly, without midwives, there is little chance that MMRCs will seriously examine the harm caused by the normalized medical model of birth and its overuse of interventions or seriously consider the many benefits of midwifery care and out-of-hospital birth in addressing maternal mortality.

Thus, while the problem of birth injury has been escalating over multiple decades, the state has done little to prevent or combat this harm or to remedy the potential for corruption in its limited attempts to find a solution. In sum, the state is failing birthing women.

\section{Privatized Pregnancy}

Why has so little been done to address the rapidly growing problem of birth injury in the United States? This Part argues that birth is both rhetorically and legally privatized in a way that absolves the state of responsibility to adopt meaningful solutions to prevent birth injury, including wide-scale adoption of midwifery and out-of-hospital birth.

Our current legal and political system privatizes pregnancy in a number of ways. The notion of the fully informed autonomous patient justifies the relegation of birth to the private sphere. All aspects of prenatal care and birth are viewed as private deliberations between and a woman and her doctor. Thus, birth injury is framed as the result of interpersonal conflicts between a physician and a woman as a fully autonomous actor whose "rights" have been violated. Pregnant women are falsely framed as unencumbered consumers who can freely shape their birth experiences through market participation and thus do not need support from the state. Emphasis on individual choice in birth facilitates punitive state response when a woman makes the "wrong" choice that may harm her fetus. This excessive focus on individual rights and individual harm not only precludes the adoption of systemic solutions to birth injury, it further causes significant and widespread damage.

\section{A. The Problem of Individual Rights}

Birth justice rhetoric is focused almost exclusively on the individual rights of birthing women. This focus obscures the many social, economic, and legal constraints on assertion and vindication of these rights and the harm caused by placing the burden of

\footnotetext{
${ }^{226}$ California health professionals were able to cut their state MMR in half by developing and implementing standardized safety procedures aimed at reducing hemorrhage and pregnancy-induced high blood pressure (preeclampsia) during hospital birth. These procedures include the use of checklists, an equipment cart, and drills. Montagne, supra note 210.
} 
birth injury prevention solely on individual women. Litigation for violation of these "rights" pits pregnant women against medical professionals and against their fetuses. This private ordering erroneously positions mother and physician as autonomous equals, foreclosing meaningful examination of the inherent power imbalance. Further, these individual lawsuits rarely lead to systemic change and are more reactive than proactive. Importantly, the excessive individualism of these rhetorical and legal "solutions" obscures state responsibility for birth.

Well-meaning birth advocates often focus on ensuring that women are aware of their "rights" during medical birth. ${ }^{227}$ For example, the non-profit National Partnership for Women and Families has published a list of twenty rights of childbearing women. ${ }^{228}$ The list contains some aspirational items, such as a right to health care, but otherwise enumerates rights guaranteed or "probably" guaranteed by the U.S. legal system as a result of various case outcomes. ${ }^{229}$ These rights can roughly be categorized as the right to refuse medical interventions; the right of informed consent as to the benefits and risks of interventions; the right to privacy; and the right to choose all aspects of the birthing experience, including the provider, setting, partners, and hospital discharge date. ${ }^{230}$

Birth injury is typically litigated by and against private parties through the tort system, conceptually positioned as a violation of a patient's "right" to informed consent or a patient's "right" to refuse medical treatment. While the feminist movement of the 1970s may not have been successful at reviving the midwifery model of birthing care, it was instrumental in furthering the development of medical tort law and the emergence of the patient as a rights-bearing subject. ${ }^{231}$

\footnotetext{
227 See, e.g., Know Your Rights: Legal and Human Rights in Childbirth, BIRTH MonOPOLY, https://birthmonopoly.com/know-your-rights-course [https:/perma.cc/H5RH-3534]; BIRTH RTS. BAR AsS'N (BRBA), KNOW YOUR RiGHTS, https://birthrightsbar.org/resources/Documents/brba-know-your-rights.pdf [https://perma.cc/V3VU-7JDZ].

${ }^{228}$ ChildBirth Connection, The Rights of ChildBeARing Women, https://www.nationalpartnership.org/our-work/resources/health-care/maternity/the-rights-of-childbearingwomen.pdf [https://perma.cc/UG9T-GDU9].

229 Id.

$230 \mathrm{Id}$

${ }^{231}$ Nan D. Hunter, Rights Talk and Patient Subjectivity: The Role of Autonomy, Equality, and Participation Norms, 45 WaKe Forest L. REV. 1525, 1528 (2010).
} 
The law of informed consent, originally developed in response to experiments conducted by Nazi physicians, strengthened significantly during the 1970 s. ${ }^{232}$ This law articulates an affirmative duty by physicians to provide the patient with the "facts which are necessary to form the basis of an intelligent consent." ${ }^{, 233}$ ACOG has defined informed consent as "the willing acceptance of a medical intervention by a patient after adequate disclosure by the physician of the nature of the intervention with its risks and benefits and of the alternatives with their risks and benefits." 234 This recognition of patient autonomy is described as "the most well-known principle of medical ethics." 235

The right to refuse medical treatment during birth is also invoked against the state when medical professionals seek court-ordered intervention. The Supreme Court has fully established the right to refuse unwanted medical treatment as a substantive due process right. ${ }^{236}$ However, this right is not absolute for birthing women, as it is often weighed against state interest in fetal health. ${ }^{237}$

For a variety of reasons, tort litigation for birth injury is rarely successful. As a result, advocates and scholars have proposed addressing obstetric violence as a form of gender or racial discrimination or a violation of a human right to privacy or bodily integrity. Even if it were possible to vindicate such rights in the U.S. legal system, these solutions still operate within the same excessive individualism that confines pregnancy to the private sphere and forecloses meaningful state support.

This section outlines the problems with framing birth injury solely as a violation of individual rights. By focusing on individual action and harm, this framing not only

${ }^{232} I d$.

${ }^{233}$ Ruth FAden \& Tom L. BeAuchamp, A History And Theory of Informed Consent 125 (1986).

${ }^{234}$ Am. Coll. of Obstetricians \& Gynecologists (ACOG), Comm. on Ethics, Committee Opinion: Ethical Decision Making in ObStetrics and Gynecology 5 (Dec. 2007, reaff'd 2016) (quoting Albert R. Jonsen, Mark Siegler \& William J. Winslade, Clinical Ethics: A Practical Approach to Ethical DeCisions IN CliniCAL Medicine (6th ed. 2006)), https://www.acog.org//media/project/acog/acogorg/clinical/files/committee-opinion/articles/2007/12/ethical-decision-making-inobstetrics-and-gynecology.pdf [https://perma.cc/KEN4-6QFY].

235 Jaime King \& Benjamin Moulton, Rethinking Informed Consent: The Case for Shared Medical DecisionMaking, 32 AM. J.L. \& MED. 429, 435 (2006).

${ }^{236}$ Cruzan ex rel. Cruzan v. Dir., Mo. Dep't of Health, 497 U.S. 261, 278 (1990).

${ }^{237}$ Kukura, Choice in Birth, supra note 109, at 992-93. 
prevents the adoption of systemic solutions, it further injures birthing women by placing them in conflict with their fetuses and transforming the birth experience from celebratory to adversarial.

\section{All Rights Are Not Exerted Equally}

The rhetoric of patients' rights incorrectly places the burden of birth injury prevention solely on the pregnant woman. This positioning completely obscures the many social, economic, cultural, and religious factors that constrain a birthing woman's ability to assert these rights during and after childbirth.

\section{a. Know Your Rights?}

As an initial matter, many women are not fully aware of their "rights" regarding birth. Only $62 \%$ of women surveyed in 2002 said they fully understood their right to receive complete explanations of any procedure, drug, or test offered to them during pregnancy and childbirth, and only $66 \%$ said they fully understood their right to refuse any procedure, drug, or test offered. ${ }^{238}$ This lack of awareness can easily be understood in light of the social, political, and religious factors that may disadvantage a woman's ability to access or understand this information. There is no single authoritative document legally granting rights to U.S. women during childbirth. And there is no mandate that physicians or other professionals inform pregnant women of any rights, including the right of informed consent or refusal of medical treatment. Even if required, it is questionable whether a medical professional could or would adequately explain these rights due to institutional conflicts of interest. Thus, the onus is on the pregnant woman to discover this information on her own. She may or may not receive some explanation of these rights from birthing classes, partners, or the community. It is completely dependent upon her social context.

\section{b. Stand Up for Your Rights?}

Simply ensuring that all pregnant women are aware of their rights during childbirth will not fully prevent birth injury. Even when a woman knows her rights, she may not be willing or able to assert them. Social, religious, and cultural factors, such as limited grasp of the English language or beliefs about respecting authority, may cause women to accept

\footnotetext{
${ }^{238}$ Eugene DeclercQ et AL., Maternity Ctr. Ass'N, Listening to Mothers: Report of the First NATIONAL U.S. SuRVEY OF WOMEN's ChILDBEARING EXPERIENCES 46 (2002), https://www.nationalpartnership.org/our-work/resources/health-care/maternity/listening-to-mothersi_2002.pdf [https://perma.cc/EV89-YBN9].
} 
medical judgments without question. Additionally, scholars argue that women's behavior during birth is often shaped by gendered expectations that would cause them to "worry about being nice, polite, kind and selfless in their interactions during labour and childbirth." 239

Furthermore, a woman's "right to choose" all aspects of her birthing experience is significantly constrained by socio-economic factors. A woman's choice of provider, location, and use or non-use of interventions during birth may be severely limited by her insurance plan or available funds. Many women live in rural or low-income areas with limited prenatal care options. In 2018, the March of Dimes found that more than five million women lived in counties with no obstetric care or obstetric providers. ${ }^{240}$ Unsurprisingly, these counties had a higher poverty rate and lower median household income than counties with access to maternity care. ${ }^{241}$ Close to half of all U.S. counties lacked even a single OB/GYN. ${ }^{242}$ An additional ten million women lived in counties with "limited access to maternity care," defined by a combination of fewer than two hospitals, fewer than sixty OB providers per 10,000 women, and lower proportions of women with health insurance. ${ }^{243}$ In fact, more than ten million women in the United States did not have health insurance at all. ${ }^{244}$ These millions of women are hardly able to avoid rights violations by simply purchasing an ideal birth experience.

\section{c. Rights Without Remedy?}

There are also significant social, cultural, and economic constraints on a woman's ability to seek redress for birth injury through tort litigation.

\footnotetext{
239 Judith McAra-Couper, Marion Jones \& Liz Smythe, Caesarean-Section, My Body, My Choice: The Construction of 'Informed Choice' in Relation to Intervention in Childbirth, 22 FEMINISM \& PSYCH. 81, 89 (2011).

${ }^{240}$ March of Dimes, Nowhere to Go: Maternity Care Deserts Across the U.S. 1 (2018), https://www.marchofdimes.org/materials/Nowhere_to_Go_Final.pdf [https://perma.cc/RXE9-UPXF]. 
First, it can be extremely difficult for women to find attorneys to represent them. ${ }^{245}$ Attorney fees are often prohibitively high. ${ }^{246}$ There is little incentive for attorneys to take a case on contingency when, absent severe injury to the mother or injury to the fetus, the monetary value of such lawsuits is usually very low. ${ }^{247}$ Indeed, claims of maternal harm in the tort system are often negated by the presence of healthy babies, suggesting that fetal harm dominates judicial reasoning. ${ }^{248}$

This elevation of fetal harm, mutually reinforced by the gendered norm of "selfless mother," surely prevents some women with healthy babies from even seeking redress. A woman may internalize the message that her injury is irrelevant or may abstain from filing a lawsuit out of fear that she is or will be perceived as selfish.

Further, women may be disadvantaged by the timing or nature of their injuries. Many states have short or unpredictable statutes of limitation for tort lawsuits that can bar claims. ${ }^{249}$ It can also be difficult to prove causation and damages in such a lawsuit. It may not be easy to attribute a physical or psychological injury during birth to a specific actor or actors in a medical institution, or to distinguish such harm from what may occur "naturally" during birth. ${ }^{250}$ In sum, a right does not hold much power in the face of such a significantly limited remedy.

Positioning birth injury as violation of an autonomous woman's rights allows the state to continue abdicating its responsibility to support birthing women. This fiction ignores the numerous constraints that prevent women from adequately asserting and vindicating their rights during birth and unfairly places the burden on them to do so.

\section{The Myth of the Autonomous Patient}

Framing birth injury as interpersonal conflict between a rights-bearing woman and her doctor falsely positions the two as autonomous equals. This fiction obscures the

\footnotetext{
${ }^{245}$ Diaz-Tello, supra note 104, at 59.

${ }^{246} I d$.

${ }^{247} I d$.

${ }^{248}$ Abrams, supra note 44, at 1989.

${ }^{249}$ Diaz-Tello, supra note 104, at 59.

${ }^{250}$ Abrams, supra note 44, at 1982.
} 
significantly unequal distribution of power and privilege within the doctor-patient relationship and society as a whole. In reality, the enormous societal deference accorded to medical knowledge and technological advancement significantly constrains a woman's birth experience.

\section{a. Misinformed Consent}

The doctrine of informed consent in particular masks the significant power held by physicians and medical institutions. Informed consent is often portrayed as mother and doctor engaging in shared decision-making, or even as doctors taking on a counselor role to assist and facilitate a woman's independent medical decisions. ${ }^{251}$ In reality, women's medical choices are constrained by the scope of the information made available to them and the manner in which it is delivered. The nature of a woman's relationship with her doctor and the ways in which the doctor may over or under emphasize risk, particularly as it relates to the fetus, significantly influence her choices. Institutional policies, often undisclosed, dictate if and how medical information is communicated to pregnant and birthing women. A number of structural factors may influence these and other institutional policies regarding birth. ${ }^{252}$ For example, concerns for profit and efficiency or fear of litigation motivate some hospitals and physicians to suggest elective cesarean because of its predictability and higher reimbursement rate. ${ }^{253}$

Yet the rhetoric of fully informed autonomous choice consigns women to their fate should a coerced or unnecessary intervention cause harm. The notion of informed consent can and does work against a birthing woman to justify the actions of her medical provider, who may achieve consent under duress or through selective or manipulative dissemination of information.

\section{b. Physician Knows Best}

Birthing women are also significantly disadvantaged by the powerful social belief that physicians have decision-making authority justifying threat and coercion. This elevation of authoritative medical knowledge is a powerful obstacle to winning a lawsuit

\footnotetext{
${ }^{251}$ See, e.g., What Is Informed Consent?, AM. CANCER SOC'Y, https://www.cancer.org/treatment/finding-andpaying-for-treatment/understanding-financial-and-legal-matters/informed-consent/what-is-informedconsent.html [https://perma.cc/NM5V-XTD8] (classifying shared decision-making as part of the informed consent process).

${ }^{252}$ See supra Part I for a discussion of systemic factors contributing to obstetric violence.

${ }^{253}$ Kukura, Obstetric Violence, supra note 93, at 768-69.
} 
for birth injury or defending against attempts at court-ordered intervention. ${ }^{254}$ Even if a judge or jury does not have a "physician knows best" attitude, physicians and their medical experts have a distinct advantage in being able to offer explanations for coercive behavior that seem medically sound. ${ }^{255}$ It may be difficult to find medical experts with specialized knowledge to counter a physician's over-assertion of risk, particularly in the case of court-ordered interventions where hearings happen quickly. ${ }^{256}$ This problem may be exacerbated by the admission of recommendations by professional organizations such as ACOG as evidence of the appropriate standard of care. ${ }^{257}$ These organizations may also be motivated to make recommendations based on non-medical factors such as fear of litigation or market competition. ${ }^{258}$ Yet, despite this obvious deference accorded to medical professionals, we continue to maintain the fiction that individual women can vindicate their birthing rights on a level playing field.

\footnotetext{
${ }^{254}$ See Diaz-Tello, supra note 104, at 59 (noting the tendency of judge and jury to defer to physicians); Ehrenreich, supra note 96, at 556-59 (discussing the "extreme" deference afforded to physician opinion, particularly in the absence of opposing expert testimony, in a hearing involving a court-ordered cesarean); Rebecca A. Spence, Abandoning Women to Their Rights: What Happens When Feminist Jurisprudence Ignores Birthing Rights, 19 CARDOZO J.L. \& GENDER 75, 84-88 (discussing several cases involving problematic deference to physician opinion, including one in which the court characterized testimony by plaintiff"s world-renowned expert on childbirth as the "rhetoric" of an "advocate").

${ }^{255}$ Juries are generally not equipped with the requisite medical knowledge to properly evaluate expert testimony regarding whether a physician was acting within the appropriate standard of care. Kukura, Obstretric Violence, supra note 93, at 787.
}

${ }^{256}$ See Ehrenreich, supra note 96, at 556-65; Spence, supra note 254, at 87 (noting that "courts need no help in deferring to the analysis or distribution of risk presented by a physician or hospital," particularly in intervention hearings that often have inadequate procedural due process).

${ }^{257}$ See Kukura, Obstetric Violence, supra note 93, at 783 (noting that "ACOG guidelines serve as evidence of the standard of care in malpractice suits, but many of them do not reflect the best available evidence about maternity care practices").

${ }^{258}$ For example, the 1999 ACOG recommendations regarding VBAC introduced a stricter standard that required the immediate availability of facilities and personnel to perform emergency cesarean delivery if necessary. As a result, VBAC rates decreased from $23.4 \%$ in 1999 to $16.4 \%$ just two years later and declined further to $10.6 \%$ in 2003. Kukura, Choice in Birth, supra note 109, at 962-64. There was evidence to suggest that ACOG was motivated to make these recommendations, at least in part, by a desire to reduce the number of malpractice lawsuits and increase profits from cesarean birth. See Lisa Chalidze, Misinformed Consent: Non-Medical Bases for American Birth Recommendations as a Human-Rights Issue 31-32 (May 17, 2008) (M.A. final project, Skidmore College) (on file with the Lucy Scribner Library, Skidmore College) (arguing that a series of ACOG statements established profit and litigation avoidance motives for restricting VBAC). 


\section{c. Technocratic Birth}

Closely related to cultural elevation of medical knowledge, the perceived superiority of technology plays a critical role in constraining birth choice. As technology has become more prevalent, some women feel that birth without intervention is "old fashioned." 259 The use of technology in birth may be viewed as more progressive, safer, or more trustworthy than "natural" birth because technology is positioned as more reliable than a woman's intuition and knowledge of her own body. ${ }^{260}$ Scholars have long explored this cultural elevation of technology over natural and biological processes. In the early 1990s, anthropologist Robbie Davis-Floyd found birth in the United States to be the "complete cultural expression of our technocratic value system."261 Davis-Floyd drew upon Peter C. Reynolds' mythology of technocracy, which argued that "technological progress" is simply a folk term for the ritual transformation of natural bodies, conceptualized as primitive and "female" into man-made ones, conceptualized as advanced, purified, and "male." ${ }^{262}$ Reynolds dubbed this transformation the One-Two Punch: Take a highly successful natural process and 1) render it dysfunctional with technology, then 2) fix it with technology. ${ }^{263}$ Reynolds viewed the One-Two punch as the "integral result of technocratic society's super-valuation of technology and science over nature." ${ }^{264}$ DavisFloyd presented birth as the "perfect example" of the One-Two punch. ${ }^{265}$ Punch One: Redefine pregnancy as a dysfunctional mechanical process by dissecting labor into component stages subjected to measurements and rules, enhanced by diagnostic technologies (such as fetal monitoring) that confirm each stage is progressing as expected and remedial technologies to make them proceed as they should if they aren't (Pitocin, episiotomy, cesarean) ${ }^{266}$ Punch Two: Transform birth into a technocratic service supplied

\footnotetext{
259 Tina Lavender \& Carol Kingdon, Caesarean Delivery at Maternal Request: Why We Should Promote Normal Birth, 14 BRIT. J. MidWIFERY 302 (2006).

${ }^{260}$ McAra-Couper, Jones \& Smythe, supra note 239, at 93.

${ }^{261}$ Robbie E. Davis-Floyd, The Technocratic Body: American Childbirth as Cultural Expression, 38 Soc. ScI. \& MED. 1125, 1126 (1994).

${ }^{262}$ Id. at 1125 (citing Peter C. Reynolds, Stealing Fire: The Mythology of the Technocracy (1991)).

${ }^{263}$ REYNOLDS, supra note 262, at 3-5.

${ }^{264} I d$.

${ }^{265}$ Davis-Floyd, supra note 261, at 1126.

${ }^{266} I d$. at 1127.
} 
by obstetricians and establish the norm of birth as a mechanical, rather than a natural process. ${ }^{267}$ Indeed, studies show that many women do not even question the use of technological interventions at birth, viewing them as an essential or necessary part of the experience. ${ }^{268}$ Thus, the cultural ascendancy of technology over nature operates as another powerful constraint on a woman's choice of birth experience.

In sum, the autonomous patient who is freely able to give informed consent or refusal and to vindicate violations of these rights is a fiction. A proper solution to birth injury must acknowledge and address the power imbalances inherent in medicalized birth.

\section{Mother Versus Fetus}

The rhetoric of individual choice also contributes to the increasing social, legal, and clinical divide between mother and fetus. This problematic framing creates an unnatural tension between mother and child, furthering discourse of the selfish mother, preventing recognition of maternal harm caused by birth trauma, justifying punitive and coercive measures rather than provision of social and economic support, and preventing us from embracing a holistic model of birth.

Technocratic birth necessarily entailed the separation of mother and fetus. As birth became a mechanical process, focus shifted to the resulting product: a perfect baby. ${ }^{269}$ The technocratic ideal of baby-as-product and the increasing availability of fetal monitoring technology combined to firmly separate fetus from mother ${ }^{270}$ :

Diagnostic technologies, from the most routine ultrasound to the most exotic embryo transplant, work towards the construction of the fetus as a separate social being. ... The history of Western obstetrics is the history of technologies of separation. We've separated milk from breasts, mothers from babies, fetuses from pregnancies, sexuality from procreation, pregnancy from motherhood .... It is very, very hard to

\footnotetext{
${ }^{267} I d$.

${ }^{268}$ See Robbie E. Davis-Floyd, Birth as An American Rite of Passage 281 (1992) (finding that 70\% of women surveyed were comfortable with their highly technological birth experiences); Coxon, Sandalla \& Fulopb, supra note 59, at 63 (reporting that none of the women surveyed were concerned about the risk posed by medical intervention, portraying such interventions as essential rescue).

${ }^{269}$ Davis-Floyd, supra note 261, at 1127.

${ }^{270} \mathrm{Id}$.
} 
conceptually put back together that which medicine has rendered asunder. . . . I find that I have a harder and harder time trying to make the meaning of connection, let alone the value of connection, understood. ${ }^{271}$

This conception of mother and fetus as separate is not "natural or even inevitable."272 It certainly does not reflect how most women perceive themselves during pregnancy. Women often view themselves as integrated with the fetus, sharing a physical and emotional bond. ${ }^{273}$ "Pregnancy dissolves the distinction between self and other, and the mother's pregnant body simultaneously contains herself and the possibility of another separate individual that for a time she experiences as herself." 274 This perception is reflected in the midwifery model of care, which treats mother and fetus as a single holistic unit. ${ }^{275}$ In contrast, the medical model of birth clearly treats woman and fetus as separate ${ }^{276}$ and often pits them against one other, justifying unwanted interventions and other mistreatment of birthing women in the name of fetal health.

As fetal monitoring and ultrasound technology developed to conceptually separate mother from fetus, the legal system furthered this divide. Roe $v$. Wade unequivocally established mother and fetus as separate, conflicting, rights-bearing subjects in the context of abortion. ${ }^{277}$ This legal positioning has been adopted in the birthing context as well, in cases involving medical professionals seeking court-ordered birth interventions and in rare constitutional or statutory challenges brought by mothers who experienced birth trauma in public hospitals. ${ }^{278}$ Courts often frame these challenges as conflicts

\footnotetext{
${ }^{271}$ Barbara Katz Rothman, Plenary Address at the Midwives Alliance of North America Conference in New York City (Nov. 1992).

${ }^{272}$ Saru M. Matambanadzo, Reconstructing Pregnancy, 69 SMU L. Rev. 187, 254 (2016).

${ }^{273}$ Stover, supra note 7, at 344-45.

${ }^{274}$ Matambanadzo, supra note 272, at 253 (citing Talia Welsh, The Order of Life: How Phenomenologies of Pregnancy Revise and Reject Theories of the Subject, in Coming to Life: Philosophies of Pregnancy, ChildbirTh, AND Mothering 283, 293 (Sarah LaChance Adams \& Caroline R. Lundquist eds., 2013)).

${ }^{275}$ See Suarez, supra note 90, at 336.

${ }^{276}$ Many medical professionals view the fetus as a "second patient." Kukura, Choice in Birth, supra note 109, at $990-91$.

277 Roe v. Wade, 410 U.S. 113, 164-65 (1973); see also LAURA M. PURDy, ReProducing PERsons: Issues IN FEMINIST BIOETHICS 91-92 (1996) (discussing conceptual separation of the rights of mother and fetus).

${ }^{278}$ Kukura, Obstetric Violence, supra note 93, at 794.
} 
between a mother's right to refuse medical treatment and the state's interest in the wellbeing of the fetus. ${ }^{279}$ In so doing, they have imported judicial reasoning from Roe to assume that the state interest in a fetus after viability trumps the woman's rights. ${ }^{280}$ Scholars have argued that this comparison is flawed because a woman who has decided to carry a child should be presumed to be making the best decisions for the fetus. ${ }^{281}$

Unfortunately, the legal system and birth justice advocates are locked in a mutually reinforcing emphasis on maternal-fetal conflict. Roe's clear separation and individualization of the fetus forced reproductive rights discourse towards positioning the fetus as something that curtails a woman's rights. ${ }^{282}$ Birth justice advocates are then effectively forced to adopt this discourse of individual choice in order to resist fetal personhood measures that could severely restrict access to abortion or further criminalize pregnant women for actions deemed harmful to the fetus. Instead of discussing the interests of mother and fetus as a single unit or as presumptively aligned, birth justice advocates must completely disavow fetal interest and focus exclusively on the rights of the individual woman. Thus, mother and fetus will always be in conflict and the state will always side with the fetus.

As this Article seeks to establish, it is vastly important that we recognize the state's interest in birth in calling for meaningful support of midwifery. The problem is not necessarily acknowledging state interest in the birthing process or even in recognizing state interest in fetal health, but rather placing fetal interest in opposition to the mother.

\section{Adversarial Birth}

Positioning birth as a battleground upon which women must fight to ensure their health and safety significantly alters what should be a meaningful, definitive, and transformative life experience. Teaching a woman that it is her responsibility to defend herself against unwanted intervention creates additional anxiety, ensuring that she will perceive her birth as a negative experience before she even enters the hospital.

\footnotetext{
${ }^{279} I d$. at $794-95$

${ }^{280} I d$. at 794.

${ }^{281} I d$. at $794-95$.

282 See Deborah J. Krauss, Regulating Women's Bodies: The Adverse Effect of Fetal Rights Theory on Childbirth Decisions and Women of Color, 26 HARV. C.R.-C.L. L. REV. 523, 544 (1991).
} 
Birth partners are also being transformed from supportive caregivers to soldiers. Childbirth education classes, when not co-opted by hospitals to provide patient education rather than birth education, ${ }^{283}$ may focus on preparing birth partners to fight for a woman's rights during labor and to guard against potential rights violations. This could generate fear and anxiety among birth partners, causing them to focus on potentially negative outcomes and detracting from the quality of support they provide during labor.

This troubling shift from support to zealous advocacy is most apparent within the community of professional birth coaches known as doulas. Doulas are paid to offer nonmedical physical and emotional support and information to pregnant women before, during, and after birth. ${ }^{284}$ Doula care during birth may include offering reassurance and praise, information and advice about labor and coping, and comfort measures such as massage and warm baths/showers. ${ }^{285}$

Recognizing the unfortunate potential for trauma and injury during hospital birth, doulas also act as advocates for birthing women. ${ }^{286}$ The scope of this advocacy has been strongly debated even within the doula community, as doulas and physicians are increasingly coming into conflict. According to the standards of practice of DONA, the largest doula certification organization in the United States, doulas are primarily meant to advocate for a client's wishes by encouraging communication between client and physician. ${ }^{287}$ Further, "[c]lients and doulas must recognize that the advocacy role does not include the doula speaking instead of the client or making decisions for the client. The advocacy role is best described as support, information, and mediation or negotiation."288 Physicians have long been concerned that doulas are "providing [untrained] medical opinions" or acting as intermediaries in a way that negatively impacts the doctor-patient

\footnotetext{
${ }^{283}$ Christine H. Morton \& Elayne G. Clift, Birth Ambassadors: Doulas And the Re-Emergence of WOMAN-SUPPORTED BIRTH IN AMERICA (2014).

${ }^{284}$ What Is a Doula?, DONA INT'L, https://www.dona.org/what-is-a-doula [https://perma.cc/YF3D-ZQSS].

${ }^{285}$ Benefits of a Doula, DONA INT'L, https://www.dona.org/what-is-a-doula/benefits-of-a-doula [https://perma.cc/YB8P-XEXE].

${ }^{286} I d$.

${ }^{287}$ DONA InT'L, StANDARDS OF Practice: BirTh Doula 3 (2017), https://www.dona.org/wpcontent/uploads/2017/08/COESOP-2020-FINAL-Birth.pdf [https://perma.cc/H35Q-LV3Q].

${ }^{288} I d$.
} 
relationship. ${ }^{289}$ Some physicians have even adopted policies prohibiting their patients from hiring doulas. ${ }^{290}$ However, some doulas feel that physicians and nurses are simply uncooperative and may unfairly assume that doulas are influencing a woman's decision to refuse intervention simply because they are in the room. ${ }^{291}$

In an extreme case, a woman with serious fear of birth trauma recently hired a "lawyer-doula" to attend her birth. ${ }^{292}$ This attorney took on the role of doula in order to be present during birth to prevent rights violations. ${ }^{293}$ The expressive implications of bringing a lawyer to your birth are bound to intensify the potential for conflict. And members of the doula community are justifiably concerned that this mixing of roles will obscure their vital support functions and further justify prohibitive action on the part of hospitals. ${ }^{294}$ Additionally, hospital birth is already an extremely expensive endeavor. Encouraging women to hire lawyers to attend birth will only make it more so, exacerbating the already disproportionate impact of birth injury on low-income women.

Further, continuing to frame birth injury solely as mother-doctor conflict may cause pregnant women to distrust their providers from the outset. Those who are financially or otherwise constrained in their choice of birth attendants could find themselves on guard

\footnotetext{
${ }^{289}$ Suein Hwang, As 'Doulas' Enter Delivery Rooms, Conflicts Arise, WALL ST. J. (Jan. 19, 2004), https://www.wsj.com/articles/SB1074468886698004731 [https://perma.cc/KG3C-S2HY].

${ }^{290}$ See, e.g., Misti Crane, Ob-Gyn Practice's Ban on Doulas Stirs Debate, Columbus Dispatch (July 2, 2010), https://www.dispatch.com/article/20100702/NEWS/307029753 [https://perma.cc/X7Y9-V82K]; Diana Spalding, Doulas Are Not Welcome with This OBGYN-And It Is Wrong on So Many Levels, MotHERLY (Aug. 20, 2019), https://www.mother.ly/news/doulas-are-not-welcome-with-this-obgyn-and-it-is-wrong-onso-many-levels [https://perma.cc/CD2X-QHVA].

${ }^{291}$ See Hwang, supra note 289 (describing one doula's experience with a physician incorrectly assuming undue influence on a decision to refuse medical intervention); Pamela Paul, And the Doula Makes Four, N.Y. TIMES (Mar. 2, 2008), https://www.nytimes.com/2008/03/02/fashion/02doula.html [https://perma.cc/VK3WDJNF] (discussing doula conflicts with nurses and physicians, stating "[d]oulas contend that doctors and nurses aren't always cooperative"); see also Michael C. Klein et al., The Attitudes of Canadian Maternity Care Practitioners Towards Labour and Birth: Many Differences but Important Similarities, $31 \mathrm{~J}$. OBSTETRICS \& GyNAECOLOGY CAN. 827, 827-40 (2009) (finding that approximately half of Canadian obstetricians and a quarter of nurses and family physicians viewed doula care unfavorably).

${ }^{292}$ Cristen Pascucci, When Your Lawyer Is Your Doula, BiRTH MONOPOLY (Oct. 23, 2018), https://birthmonopoly.com/when-your-lawyer-is-your-doula/ [https://perma.cc/R9EX-8R8M].

${ }^{293} I d$.

${ }^{294}$ See Sharon Muza, How a Doula Helps Clients to Receive Respectful Care, DONA INT'L (Oct. 26, 2018), https://www.dona.org/doula-lawyer/ [https://perma.cc/X65A-RBYB].
} 
for the duration of their pregnancy, each milestone becoming a potential conflict rather than a source of joy.

Any solution to birth injury must be framed so as to minimize distrust and unnecessary conflict between a woman and her care provider. The framing of birth injury as solely a violation of individual rights committed by individual medical providers only serves to exacerbate the fear and anxiety surrounding pregnancy, further robbing women of the celebratory birth experience they deserve.

\section{Ignoring Widespread Harm}

Framing birth injury as the violation of an individual woman's rights necessarily forecloses examination of broader social injury. Focusing on harm to individual women obscures the larger social harm caused by obstetric mistreatment and infant and maternal mortality and constrains reform to the hospital room. Birth trauma affects not only the woman, but her entire family and community. Beyond that, birth trauma negatively impacts society. Focusing on individual instances of birth trauma prevents us from addressing the larger social harm caused by the medicalization of birth and its surrounding discourse of risk. We must take a broader view in analyzing the social implications of our dominant model of childbirth, including the possibility of diminished reproduction ${ }^{295}$ and the overall financial impact of hospital care. ${ }^{296}$ The United States' "birth problem" is not limited to the hospital room. And meaningful societal change is unlikely to transpire through piecemeal retributive solutions directed at remedies for only some individuals.

\footnotetext{
${ }^{295}$ Tokophobia, the pathological fear of pregnancy and childbirth, is a growing trend in Western societies. Studies from Australia and Britain have found that $6 \%$ of pregnant women report a disabling fear of birth, while $13 \%$ of non-pregnant women are fearful enough to postpone or completely avoid pregnancy. See Kristina Hofberg \& Mark R. Ward, Fear of Pregnancy and Childbirth, 79 POSTGRADUATE MED. J. 505, 50607 (2003).

${ }^{296}$ The United States spends more on health care than any other country in the world and more on maternity care than any other health expenditure. AMNESTY INT'L, supra note 129, at 1. Birthing facilities, the overwhelmingly majority of which are hospitals, earn at least $\$ 111$ billion annually. AM. Ass'N OF BIRTH Ctrs., Preliminary Comments on the Federal Trade Commission Workshop "Examining Health Care COMPETITION" (Mar. 19, 2014),

https://www.ftc.gov/system/files/documents/public_comments/2014/03/00069-89017.pdf

[https://perma.cc/P34N-NZ7C].
} 


\section{Individual Choice Versus Social Good}

Singular focus on individual choice prevents recognition and remedy of the social harm that may result from some women's birth "choices." This section highlights two examples of this tension and the harm caused by abdication of state responsibility under the ideology of individual choice: elective cesarean and birth in the time of COVID-19.

\section{a. Elective Cesarean}

A salient example of the tension between individual choice and social good is the large number of U.S. women who elect medically unnecessary cesarean birth. Experts have attributed the comparatively high rate of cesarean birth in the United States to an increase in elective cesareans. ${ }^{297}$ As explored previously, surgical birth poses a number of significant risks to the mother and fetus, including increasing the chance of maternal death by over $60 \% .{ }^{298}$

Yet, for a variety of reasons, women are increasingly "choosing" to have cesarean birth when not medically indicated. This choice suffers from the same social constraints as any other birthing decision. However, a number of additional social values shape a woman's decision to elect cesarean birth. A New Zealand study on the construction of informed choice in childbirth found that women were strongly influenced by social factors such as control, predictability, convenience, and the normalization of surgery. ${ }^{299}$ Choice is especially constrained by the dominant worldview that favors control and predictability in all aspects of life. ${ }^{300}$ This is further compounded in the context of birth by social attitudes regarding the body as "something to be controlled and remodeled." 301 The natural noise and "messiness" of childbirth may thus be viewed as a loss of control. ${ }^{302}$ This is compounded by gendered notions of the unassuming and polite female

\footnotetext{
${ }^{297}$ See Michaeleen Doucleff, Rate of C-Sections Is Rising at an 'Alarming'Rate, Report Says, NPR (Oct. 12, 2018), https://www.npr.org/sections/goatsandsoda/2018/10/12/656198429/rate-of-c-sections-is-rising-at-analarming-rate [https://perma.cc/CGN6-8MK2].

${ }^{298}$ Fahmy et al., supra note 4, at 88.

${ }^{299}$ McAra-Couper, Jones \& Smythe, supra note 239, at 90-94.

${ }^{300} I d$. at $90-91$.

${ }^{301} I d$

${ }^{302} \mathrm{Id}$. at 92 .
} 
who does not "savagely" grunt, scream, or expel bodily fluids. ${ }^{303}$ Faced with this "chaotic, unpredictable, irrational and inconvenient nature of birth," women may opt for elective cesarean in an attempt to impose calmness and predictability and gain control of an inherently uncontrollable event. ${ }^{304}$ Cultural normalization of surgery, particularly apparent in acceptance of cosmetic surgery as "just another market commodity," may lessen resistance to cesarean birth, even when not medically indicated. ${ }^{305}$ Our "quick fix" culture that emphasizes convenience and ease, facilitated by rapid technological advances, further promotes elective cesarean as the most convenient, and therefore the best, method of giving birth. ${ }^{306}$

Those who defend a woman's right to choose surgical birth may argue that a woman has weighed the benefits and risks and made an informed decision in her and her fetus' best interest. Even if it were possible to freely make such a decision given the enormous number of constraints on choice in birth, this focus on individual deliberation ignores the wider social costs imposed by elective cesarean.

The potential for harm from elective cesarean extends well beyond the individual woman and her fetus. The midwifery profession is certainly harmed by the continued use of elective cesarean. Physicians are motivated to promote elective cesarean as a way to maintain their monopoly on birth. The more normalized surgical birth becomes, the less women will employ midwives. And, of course, this normalization prevents the widespread adoption and support of midwifery that this Article argues is crucial to preventing societal harm from birth injury. Further, there are significant social costs associated with the unnecessary and excessive use of medical resources:

A CS [cesarean section] which is done because a woman chooses it requires a surgeon, possibly a second doctor to assist, an anesthesiologist, surgical nurses, equipment, an operating theatre, blood ready for transfusion if necessary, a longer post-operative hospital stay, etc. This costs a good deal of money and, equally importantly, a great deal of training of health personnel, most of which is at government expense, even if the CS is done by a private physician in a private hospital. If a woman receives an elective CS simply because she prefers

\footnotetext{
${ }^{303} \mathrm{Id}$. at 91 .

${ }^{304}$ Id. at 92 .

${ }^{305} I d$.

${ }^{306}$ Id. at $92-94$.
} 
it, there will be less human and financial resources for the rest of health care. ${ }^{307}$

Clearly the "right to choose" unnecessary surgical birth imposes a high social cost. It is the responsibility of the state to recognize and mitigate this social injury and to address the myriad social factors influencing this "choice." Yet the powerful ideology of individual choice prevents the state from acting to either regulate or outright prohibit elective cesarean. Further, the state is unlikely to take even small steps to reduce the number of elective cesareans by promoting midwifery and normalizing birth without intervention when surgical birth is rhetorically privatized, obscuring social harm.

\section{b. Pandemic Birth}

Birth in the time of COVID-19 perfectly exemplifies the harm caused by the privatization of pregnancy and its attendant lack of state response. In March 2020, the United States began to feel the devastating effects of COVID-19, a novel coronavirus that causes mild to fatal respiratory illness. ${ }^{308}$ As of January 2021, the virus has killed over four hundred thousand Americans and infected millions more. ${ }^{309}$ The COVID-19 pandemic has affected birthing women in a number of unique ways, exposing the great need for widespread support of midwifery and non-medical birth. This pandemic highlights the tension between individual choice and collective good, as optimal public health measures to stop the spread of the virus and adequately distribute medical resources would necessarily restrict the "choices" available to birthing women. At the same time, the ideology of individual choice allows the state to abdicate responsibility for implementing these measures, leaving citizens on their own to decide how best to safely give birth in the time of COVID-19.

Amidst the chaos of the pandemic, birthing women face unexpected new restrictions. In an effort to slow disease transmission and alleviate resource strain, hospitals around the country instituted policies barring all visitors from labor and postpartum units, effectively leaving women to birth entirely alone without partners, doulas, or family

\footnotetext{
${ }^{307}$ Marsden Wagner, Choosing Caesarean Section, 356 LANCET 1677, 1679 (2000).

${ }^{308}$ Dakin Andone et al., Second Coronavirus Death Reported in the United States and First Case Confirmed in New York, CNN (Mar. 2, 2020), https://www.cnn.com/2020/03/01/health/us-coronavirussunday/index.html [https://perma.cc/P52A-ZT4B].

${ }^{309}$ See Patricia Mazzei, The Virus Death Toll in the U.S. Has Passed 400,000, N.Y. Times (Jan. 19, 2021), https://www.nytimes.com/2021/01/19/us/coronavirus-deaths-usa-400000.html (reporting over 24 million cases and over 400,000 deaths in the United States from COVID-19).
} 
members. ${ }^{310}$ Birthing professionals opposed the move not only because isolating women and preventing partners from participating in the birth experience would cause emotional trauma, but because health outcomes would be worsened without continuous support to prevent unnecessary medical intervention. ${ }^{311}$ They also argued that the policies would put additional strain on doctors and nurses, who would have to perform the support functions previously provided by birth partners ${ }^{312}$ Ultimately, CDC recommended that hospitals limit birthing support to one person. ${ }^{313}$ Still, an early study indicated that many women were told by hospitals that they had to birth alone. ${ }^{314}$ Additionally, some faced immense pressure to deliver by elective cesarean, ${ }^{315}$ either as a "solution" to facing hours of labor alone or as a way to efficiently utilize hospital resources.

The state must do more for birthing women than merely issuing recommendations to health professionals. The state's reluctance to regulate hospital policy is likely due to the perceived privacy of the doctor-patient relationship, which this Article demonstrates should not be applicable to birth at all, let alone when facing a public health crisis. Yet at least one government official has taken action to ensure that women do not have to birth alone. In late March, New York Governor Andrew Cuomo issued an executive order mandating that hospitals allow all laboring women to have one support person. ${ }^{316}$ Still, women in most other states are at the mercy of the private hospital system.

\footnotetext{
${ }^{310}$ Meredith Blake, Women in New York Giving Birth Alone May Be Facing Their 'Worst Nightmare, 'L.A. TIMES (Mar. 26, 2020), https://www.latimes.com/world-nation/story/2020-03-26/coronavirus-childbirthalone-new-york-fear-medical-risk.

${ }^{311} I d$.

${ }^{312} I d$.

${ }^{313}$ Zaneta Thayer, U.S. Coronavirus Advice Is Failing Pregnant Women, SAPIENS (May 21, 2020), https://www.sapiens.org/biology/covid-19-and-childbirth/ [https://perma.cc/Y9UB-LUEK].

${ }^{314} \mathrm{Id}$.

${ }^{315}$ Irin Carmon, 'They Separated Me From My Baby': Hospitals Are Keeping Newborns From Their Parents Over Coronavirus Fears, CuT (Apr. 7, 2020), https://www.thecut.com/2020/04/coronavirus-newbornshospitals-parents.html [https://perma.cc/A93J-6QZA].

${ }^{316}$ N.Y. Exec. Order No. 202.12 (Mar. 28, 2020),

https://www.governor.ny.gov/sites/governor.ny.gov/files/atoms/files/EO_202.12.pdf [https://perma.cc/Y5V4BV6T].
} 
Worse yet, many hospitals are separating mother and newborn immediately after birth, sometimes for days while awaiting test results. ${ }^{317}$ In some cases, women are not even told about this separation policy in advance. ${ }^{318}$ Besides causing extreme birth trauma, even PTSD, separation robs newborns of vital early bonding via skin-to-skin contact and breastfeeding. ${ }^{319}$ Further, new mothers may have trouble pumping breast milk, requiring newborns to consume formula when those exposed to COVID-19 would likely benefit from antibodies in breast milk. ${ }^{320}$

Once again, state response to this harm is minimal and focused on preservation of individual "choice." While WHO cautions against separation and recommends breastfeeding while wearing a mask, $\mathrm{CDC}$ recommendations emphasize the risk of COVID-19 and instruct health professionals to inform women of the "costs and benefits" of separation and require the woman to decide. ${ }^{321}$ Just as with any other "right" in childbirth, there are a number of reasons it is unfair to place the burden of this decision making on a birthing woman. Importantly, she may have inadequate access to information or be unable or unwilling to make this decision or question medical judgment. This is demonstrated by an early study indicating that many women were still not clear if they were allowed to actually refuse separation after their physicians had already informed them of these costs and benefits. ${ }^{322}$ Even assuming that women are adequately informed, there are a variety of reasons that they might "choose" separation, not least of all extreme fear for the safety of their newborns. It is particularly unfair of the state to create additional fear and anxiety about the birthing experience by forcing women to face the traumatic possibility of being separated from their new babies.

While the lack of state regulation of hospital birth is problematic, it is even worse that the state effectively put the hospitals in this position in the first place. Better overall pandemic support would have significantly reduced the pressure on hospitals and medical professionals. Yet, despite months of warning, the U.S. administration failed to

\footnotetext{
${ }^{317}$ Carmon, supra note 315.

${ }^{318} I d$.

${ }^{319}$ Thayer, supra note 313.

${ }^{320} \mathrm{Id}$

${ }^{321} I d$.

${ }^{322} \mathrm{Id}$
} 
implement any sort of plan to combat the pandemic. ${ }^{323}$ State and local governments were forced to decide whether to shut down businesses and schools, and they often refused to take decisive action, leaving individuals to "choose" the correct course of action to slow disease transmission. ${ }^{324}$ The state provided little uniform or non-politicized public health guidance to aid in making this "choice." ${ }^{325}$ Even when public health experts provided clear guidelines to prevent virus transmission, the state was often slow to act ${ }^{326}$ and failed to issue mandates, choosing only to "recommend" that people take critical life-saving measures. ${ }^{327}$ Epidemiologists have found that $90 \%$ of U.S. coronavirus deaths could have been prevented had we implemented social distancing measures even two weeks earlier. ${ }^{328}$ Yet the state was loath to interfere with individual choice or with the free market, emphasizing the harm in "shutting down" the economy. ${ }^{329}$ Notably, the state also failed to implement an adequate plan for testing and contact tracing, a strategy used by other countries to combat the virus. ${ }^{330}$ Unsurprisingly, the virus spread rapidly and filled

\footnotetext{
${ }^{323}$ George Packer, We Are Living in a Failed State, AtLANTIC (June 2020), https://www.theatlantic.com/magazine/archive/2020/06/underlying-conditions/610261 [https://perma.cc/MK9W-MQND].

${ }^{324} I d$.

${ }^{325} I d$.

${ }^{326}$ Martin Pengelly, Fauci Confirms New York Times Report Trump Rebuffed Social Distancing Advice, GUARDIAN (Apr. 12, 2020), https://www.theguardian.com/world/2020/apr/12/fauci-trump-rebuffed-socialdistancing-advice-coronavirus [https://perma.cc/V8XS-QSYQ].

${ }^{327}$ Packer, supra note 323.

${ }^{328}$ Britta L. Jewell \& Nicholas P. Jewell, Opinion, The Huge Cost of Waiting to Contain the Pandemic, N.Y. Times (Apr. 14, 2020), https://www.nytimes.com/2020/04/14/opinion/covid-social-distancing.html [https://perma.cc/9TRZ-PGTG].

${ }^{329}$ Gregg Gonsalves \& Amy Kapczynski, Markets v. Lives, Bos. Rev. (Mar. 27, 2020), http://bostonreview.net/science-nature/gregg-gonsalves-amy-kapczynski-markets-v-lives [https://perma.cc/7YG2-M2EA].

${ }^{330}$ Robinson Meyer, There's One Big Reason the U.S. Economy Can't Reopen, AtLAnTIC (May 8, 2020), https://www.theatlantic.com/science/archive/2020/05/theres-only-one-way-out-of-this-mess/611431/ [https://perma.cc/B2M8-VQ3T].
} 
many hospitals to capacity. ${ }^{331}$ Hospitals also ran out of critical equipment such as test kits, ventilators, masks, and gowns, and the state was unable to supply them. ${ }^{332}$

For their part, hospitals were seemingly doing their best to combat the novel virus. In early days, testing for COVID-19 was limited, and it often took days to receive results. ${ }^{333}$ Visitor restrictions and maternal-newborn separation policies were arguably necessary in such a situation, even when weighed against the harm they caused. Health professionals were understandably concerned about the virus - the effects of which were largely unknown - fatally spreading to new mothers, their babies, and even the medical staff themselves. ${ }^{334}$ State support in achieving faster and more widespread testing, coupled with other public safety measures such as mandatory social distancing, would likely have obviated the need for the implementation of such draconian hospital policies.

Had the state already been supportive of midwifery and out-of-hospital birth, this resource strain could have been largely avoided. There could have been more birthing centers, more midwives, and better insurance coverage already available to support birthing women and free up valuable hospital resources to respond to the pandemic. Over time, state promotion of midwifery would have crucially shifted the cultural discourse of birth from private medical event to natural social event, causing more women to plan outof-hospital births. Thus, when the pandemic hit, fewer women would have faced these restrictive hospital policies and more hospital resources would be available to respond to actual medical emergencies. Long-term normalization of birth without medical intervention would have helped alleviate the perception that birthing without a physician and hospital poses too great a risk, allowing more women to feel comfortable choosing home birth if they feared virus transmission or wanted to help eliminate the strain on hospitals.

Still, mandatory out-of-hospital birth for low-risk pregnancies may be the optimal solution in this time of public health crisis. Yet the same constraints that prevent even the most basic support for midwifery operate to prevent the state from implementing this mandate. Even if the state could marshal the resources necessary to achieve this in a short

\footnotetext{
${ }^{331}$ Nicholas Bogel-Burroughs \& Sarah Mervosh, U.S. Hospitalizations for the Coronavirus Near April Peak, N.Y. TIMES (July 22, 2020), https://www.nytimes.com/2020/07/22/us/coronavirus-hospitalizations-nearpeak.html [https://perma.cc/Y6RT-N8P4].

332 Packer, supra note 323.

${ }^{333}$ Carmon, supra note 315.

${ }^{334}$ Id.
} 
time, such a ban on hospital birth would be met with significant criticism as state overreach. The hegemonic medical model of birth and social valorization of individual choice will powerfully influence public attitudes toward state response. With a faction of the population challenging state requirements to wear a mask as intrusions on individual liberty, ${ }^{335}$ it is hard to imagine that restricting a woman's "choice" of hospital birth would not be met with great resistance. Further, medical professionals and institutions are powerfully motivated to resist such a mandate for fear that it will lead to long-term profit decrease.

If we are able to overcome the rhetoric of minimal state inference and implement such a solution, the harm caused by sacrifice of individual choice should be addressed. Individual women will suffer emotional harm caused by the seeming loss of control over birthing decisions, particularly under the current social construction of pregnancy as medically risky. The state must respond by mitigating the many social, cultural, and economic factors that shape a woman's "decision" to birth in a hospital.

This pandemic has amply demonstrated the public harm caused by our continued privatization of pregnancy and birth. Yet it offers an opportunity to rethink the excessively individualistic focus on rights, choice, and control that currently pervades our approach to many social issues, including birth. Especially in times of public health crisis, individual needs must give way to the greater good. But we must also be able to rely on the state to provide crucial economic, physical, and social support to lessen the harm. Without adequate state response, individual women are abandoned to privately navigate birth amidst even greater fear and uncertainty. Those who reproduce society deserve better.

Thus, there is simply no room for the notions of state responsibility and social justice in a system that exclusively focuses on birth injury as a violation of individual rights perpetuated by individual doctors. The state is unlikely to affirmatively address the widespread harm caused by the medical model of birth if it is allowed to continue abdicating its responsibility for birth to individual women and the marketplace.

\section{B. With Great Freedom Comes Great Responsibility}

Because pregnancy is viewed as the product of individual choice, pregnant women are held entirely responsible for managing the risk of pregnancy and are punished by the

\footnotetext{
${ }^{335}$ Kwame Anthony Appiah, The True Face of Freedom Wears a Mask, WALL ST. J. (Aug. 6, 2020), https://www.wsj.com/articles/the-true-face-of-freedom-wears-a-mask-11596727495 [https://perma.cc/6UARPKWZ].
} 
state when they make a "bad choice" that may cause harm to the fetus. The rhetoric of pregnancy as medically risky justifies the categorization of pregnant women as "at risk," a stigmatizing label that places the focus on the individual rather than on the state or its societal institutions. ${ }^{336}$ Accordingly, responsibility for risk shifts from the state to individuals in the private system. When the state does get involved, its response is often punitive. Further, because a woman is held individually responsible for the outcome of her birth, each decision she makes during pregnancy may be subjected to intense social scrutiny and judgment. The paternalistic and punitive nature of current state and social involvement understandably causes advocates to double down on pregnancy as private individual choice. Unfortunately, this response only serves to confine the state and society to their limited roles.

\section{Punishing Pregnancy}

The restrained state's current involvement in pregnancy and birth is almost entirely punitive. Rather than providing much-needed social and economic support, the state only "intervenes" in the interest of fetal health to punish the autonomous pregnant woman who is individually responsible for making a "bad choice" that could harm her fetus. As such, pregnancy is becoming increasingly criminalized under the mantra of individual responsibility. Women are facing criminal prosecution and termination of parental rights for a number of "decisions" made during pregnancy, such as refusing medical intervention, using drugs and alcohol, and self-harm. ${ }^{337}$ Not only have these punitive responses failed to improve birth outcomes, they have caused additional harm to birthing women and their families. ${ }^{338}$

\footnotetext{
${ }^{336}$ Martha Albertson Fineman, "Elderly" as Vulnerable: Rethinking the Nature of Individual and Societal Responsibility, 20 ELDER L.J. 71, 106 (2012).

${ }^{337}$ Dara Purvis, The Rules of Maternity, 84 TENn. L. REV. 367, 377-91 (2017); Paltrow \& Flavin, supra note 113; Cortney Lollar, Criminalizing Pregnancy, 92 IND. L.J. 947 (2017). It is also estimated that several hundred women in the United States have been prosecuted for pregnancy outcomes of miscarriage or stillbirth. Editorial Board, When Prosecutors Jail a Mother for a Miscarriage, N.Y. TimEs (Dec. 28, 2018), https://www.nytimes.com/interactive/2018/12/28/opinion/abortion-pregnancy-pro-life.html [https://perma.cc/5HDE-KBFL].

${ }^{338}$ Punitive state responses such as these cause substantial harm to pregnant women and their families. Prison conditions can be harmful to the health of pregnant and birthing women. Incarcerated women rarely receive meaningful treatment for drug addiction. Incarceration also harms the families that these women leave behind. The involvement of child welfare authorities can interrupt crucial maternal-newborn bonding and have devastating effects on the entire family, subjecting them to surveillance and scrutiny that could ultimately lead to removal of the child from the home and termination of parental rights. See Kukura, Obstetric Violence, supra note 93, at 747-50.
} 
Because the current state response to pregnancy and birth is often either punitive or coercive, calls for birth justice are often cloaked in the language of minimal state interference. This framing, however, forecloses the possibility of meaningful state response by imposing no positive obligations on the state to support birthing women. Rather than demonizing state involvement entirely, we should be criticizing the nature of the state's involvement and examining the root causes of its punitive, paternalistic, and coercive involvement in pregnancy. This includes acknowledging the role played by the reproductive justice rhetoric of individual choice, which fully condones a restrained state in all but the most egregious circumstances, therefore requiring a punitive response.

Thus, the state continues to abdicate its responsibility for birth by placing the onus of managing the "risk" of pregnancy entirely on the birthing woman. Advocates allow the state to shirk its responsibility by continuing to emphasize pregnancy as private, in response to the punitive and paternalistic nature of current state and social involvement. Yet emphasis on individual choice and concomitant individual responsibility justifies punitive response. Instead, we must recognize birth as a collective responsibility. Anything less than a safe, healthy, positive birth experience is a social failure for which the state, not the individual woman, should take responsibility.

\section{Should You Drink That?}

Pregnancy and birth are undeniably social. As Professor Saru M. Matambanadzo argues, pregnancy is not simply biological, but is also the product of social and cultural construction. ${ }^{339}$ This is demonstrated by the overwhelming social construction of pregnancy as a risky process in need of medical intervention. Further, the physical visibility of later-stage pregnancy ensures some level of social involvement. This may take the form of well-meaning strangers attempting to touch a pregnant woman's belly. It may also take on a more "judgmental" form. Professor Dara Purvis highlights a number of cases of pregnant women being subjected to the "social judgment" of passersby for engaging in activities that are viewed as harmful to the fetus, such as drinking alcohol or caffeinated beverages, eating sushi, lifting heavy packages, exercising, or cleaning cat litter boxes. ${ }^{340}$ Exchanges such as these are almost uniformly characterized as unwanted paternalistic surveillance and criticism.

\footnotetext{
${ }^{339}$ Matambanadzo, supra note 272, at 243.

${ }^{340}$ Purvis, supra note 337 , at 378.
} 
It is imperative that both society and the law acknowledge pregnancy and birth as a collective responsibility rather than an individual one. ${ }^{341}$ We cannot achieve this by denying social involvement in pregnancy as undesirable interference with maternal choice. Rather than vilify often well-intentioned community members, we should seek to correct the source of their seemingly paternalistic or ill-informed advice, which often stems from medicalized discourse that over-emphasizes risk and the false notion of maternal-fetal conflict. Further, we must combat the rhetoric of individual responsibility that relegates the social role to blaming pregnant woman for "risky" decisions rather than providing positive support.

Thus, it is clear that we cannot adequately address birth injury by continuing to view birth solely as the product of individual choice and private relations between patient and doctor. Instead of demonizing state and social involvement, we must embrace our collective responsibility for birth and call upon the state to provide meaningful support. Further, we must recognize that medicalization has transformed birth from a natural process to a mechanical, risky, and isolated market transaction. A meaningful solution to the problem of birth injury must address the harm caused by this transformation.

\section{Towards a Responsive State}

How might we achieve meaningful support of birth? This Part first provides a theoretical framework for establishing state responsibility and then recaps a number of actions that a more responsive state could take to improve birth through the promotion and support of midwifery.

\section{A. From Restrained to Responsive}

A better approach to establishing state responsibility for birth would reframe state involvement in birth as proactive, positive, and supportive rather than punitive and reactionary. Professor Martha Fineman's vulnerability theory offers such an approach. ${ }^{342}$ Vulnerability theory begins with the recognition that, as embodied beings that are constantly susceptible to changes in our physical and social well-being, we are all

\footnotetext{
${ }^{341}$ See Matambanadzo, supra note 272, at 254 (acknowledging the former European Community's foundational legal principle that "childbearing is a societal good" and calling for communal responsibility for pregnancy in the United States).

${ }^{342}$ See generally Martha Albertson Fineman, The Vulnerable Subject: Anchoring Equality in the Human Condition, 20 Yale J.L. \& Feminism 1 (2008).
} 
universally vulnerable. ${ }^{343}$ The severely restrained state can play only a limited role in protecting the autonomous, independent, and self-sufficient legal subject from any constraint on the exercise of her autonomy. ${ }^{344}$ In contrast, vulnerability theory requires a responsive state that affirmatively addresses the vulnerability of its subjects. ${ }^{345}$ It does so by providing its citizens with the resources needed to maintain resilience in all life stages, including pregnancy. ${ }^{346}$ This collective responsibility for pregnancy and birth stems in part from the collective debt owed to pregnant women because they are reproducing society. ${ }^{347}$

Insistence on a restrained state ignores this responsibility, but also ignores current reality. The legal system's treatment of the doctor-patient relationship as private is fiction. The state is already involved in this relationship by regulating the medical industry, particularly through licensing. As a societal institution that provides resources needed for resilience, the "content and meaning" of the medical institution is and should be defined by the state. ${ }^{348}$ Further, the public already bears the cost of these "private" decisions between a woman and her physician. For example, the annual social and health cost of preterm or low-birthweight births, important predictors of infant mortality, was at least $\$ 26.2$ billion in the United States in $2005 .{ }^{349}$ In 2018 alone, government funding covered the medical costs of $43 \%$ of U.S. births. ${ }^{350}$ These are just some of the ways in which the public is currently responsible for "private" pregnancy outcomes. Arguing for

\footnotetext{
${ }^{343}$ Martha Albertson Fineman, Injury in the Unresponsive State: Writing the Vulnerable Subject Into NeoLiberal Legal Culture, in InJury AND InJustice: The Cultural Politics of HaRm ANd Redress 50, 58 (Anne Bloom, David M. Engel \& Michael McCann eds., 2018).

${ }^{344} I d$. at $66-67$.

${ }^{345} \mathrm{Id}$

${ }^{346} I d$. at $63-64$.

${ }^{347}$ Fineman applies a similar analysis to caregivers, arguing that without caretaking, there could be no society. Thus, society owes a collective debt to caregivers, whose labor produces and reproduces society. This debt should motivate us to formulate a theory of collective responsibility for caregivers. Martha Albertson Fineman, Cracking the Foundational Myths: Independence, Autonomy, and Self-Sufficiency, 8 AM. U. J. GENDER SOC. POL'Y \& L. 13, 19 (1999).

${ }^{348}$ See Fineman, The Vulnerable Subject and the Responsive State, supra note 8.

${ }^{349}$ Kelli A. Komro et al., The Effect of an Increased Minimum Wage on Infant Mortality and Birth Weight, 106 Am. J. Pub. Health 1514, 1514-16 (2016).

${ }^{350}$ MACPAC, supra note 180 , at 1.
} 
increased privatization in the face of this knowledge ignores our widespread social obligation to support safe and healthy societal reproduction.

Importantly, by recognizing the social nature of birth, vulnerability theory properly places responsibility for pregnancy and birth with the state rather than the individual woman. Recognizing state responsibility for pregnancy and birth necessarily imposes positive obligations on the government to provide the social and economic support needed to address maternal and fetal mortality, poverty, unintended pregnancy, and drug and alcohol abuse. The state is further obligated to examine the quality and accessibility of birth care and its accompanying cultural and social norms. This includes actively addressing the harm caused by excessive medicalization. ${ }^{351}$

Midwifery could play a powerful role in preventing birth injury if bolstered by the state. Yet the state has done little to even meaningfully examine birth injury, let alone address it. Instead, the restrained state continues to abdicate responsibility for birth to the marketplace, hiding behind the fiction of the autonomous doctor-patient relationship. Arguments rooted in individual choice and consumerism have not and will not impose the necessary positive obligations on the state to combat the harm caused by excessive medicalization of birth. Instead, state responsibility should be situated within a vulnerability framework, which requires the state to provide birthing women with the resources needed for resilience. Such a state is obligated to ensure the successful reproduction of society through positive, meaningful, and celebratory birth experiences. This could be achieved by taking affirmative steps to promote midwifery and normalize birth without intervention.

\section{B. Responsive Solutions}

The primary aim of this Article is not to provide concrete solutions but rather to reimagine the theoretical underpinnings of state involvement in birth care. However, this Article has explored several possible steps the responsive state could take to promote and support midwifery.

\footnotetext{
${ }^{351}$ To that end, it is imperative that the state take action to normalize birth without intervention. A woman's "choice" of birth experience is perhaps most significantly constrained by the social conception of pregnancy as risky, which is powerfully ingrained in familial and cultural norms. See Coxon, Sandalla \& Fulopb, supra note 59, at 51 (concluding that, because choice of birth location was constrained by "cultural and historical associations between birth and safety" and "prominent contemporary narratives of risk, blame and responsibility," birth in non-hospital settings would have to be "positioned as a culturally normative and acceptable practice" in order for preferences to change).
} 
First, all states should adopt comprehensive and supportive licensing and regulatory schemes. A clear and accessible licensing scheme will protect midwives from the threat of criminalization and help to legitimize and normalize the practice of midwifery. This in turn may increase physician cooperation and allow midwives to more easily obtain malpractice insurance and other necessary supplies. The state must further remove barriers to license acquisition and ensure that its midwifery regulations are not overly burdensome by restricting participation of medical professionals with conflicting economic interests in licensing boards and advisory committees.

The COVID-19 pandemic highlights the urgency of reforms such as these. Hospital resource strain could be significantly alleviated if the state took immediate steps to make out-of-hospital birth a more viable option. The pandemic has generated significant interest in home birth, as women are also fearful of contracting COVID-19 while birthing in the hospital. ${ }^{352}$ But many women are unable to pursue this option because they fear that home birth is illegal in their state or because they cannot afford to pay out of pocket. ${ }^{353}$ The state can alleviate these concerns by ending criminalization of home birth midwives and requiring private insurance providers and Medicaid to cover out-ofhospital birth. ${ }^{354}$

While these steps may go some way towards normalizing midwifery and combatting the social conception of birth as a high-risk medical event, large-scale adoption of

\footnotetext{
${ }^{352}$ See Blake, supra note 310; Marlei Martinez, Parents Turn to Home Births, Birth Centers Amid Coronavirus, KCRA 3 (Mar. 25, 2020), https://www.kcra.com/article/parents-turn-to-home-births-birthcenters-amid-coronavirus/31934885 [https://perma.cc/4VMV-URVT]; Ashley Thompson, Interest in Home Births Grows as Pandemic Reaches New Heights, CBS 46 (Apr. 1, 2020), https://www.cbs46.com/news/interest-in-home-births-grows-as-pandemic-reaches-newheights/article_9621028a-7456-11ea-9c51-439a883cce6c.html [https://perma.cc/UKH9-3NZ2]; Lisa Rayam \& Lily Oppenheimer, Childbirth and Coronavirus: The Pandemic's Toll on Atlanta Mothers and Midwives, WABE (May 4, 2020), https://www.wabe.org/childbirth-and-coronavirus-the-pandemics-toll-on-mothersmidwives-and-hospitals/ [https://perma.cc/553N-C5PW]; The Pandemic Is Making America Rethink Its Shunning of Midwifery, ECONOMIST (June 18, 2020), https://www.economist.com/unitedstates/2020/06/20/the-pandemic-is-making-america-rethink-its-shunning-of-midwifery [https://perma.ce/LPB4-HMP2]; Sophie Burkholder, COVID-19 Sparked a Rising Interest in Home Births, but Not All Can Afford Them, PHILA. InQuiRER (July 13, 2020), https://www.inquirer.com/news/midwifemidwives-birth-covid-babies-delivery-20200712.html [https://perma.cc/CRE2-9EDX].

${ }^{353}$ Thayer, supra note 313 . Note, however, that due in part to lack of state support, there are currently not enough home birth midwives to handle the higher demand. See supra note 352.

${ }^{354}$ See Brian Hill, Certified Professional Midwives Urging Governor to Relax Midwifery Regulation During Pandemic, Fox 5 ATLANTA (Apr. 9, 2020), https://www.fox5atlanta.com/news/certified-professionalmidwives-urging-governor-to-relax-midwifery-regulation-during-pandemic [https://perma.cc/32MC-AJ4G].
} 
midwifery is still unlikely if left to the free market, even with barriers to economic competition removed. As this Article has sought to establish, midwifery will not thrive if abandoned to the socially constrained "choice" of individual consumers. We need systemic change to transform birth care from a profit-driven "maternity industry" to an outcome-driven "maternity system." ${ }^{\text {"355 }}$ Mandatory midwifery care for low-risk pregnancies, as adopted by European countries through nationalized medicine, would be the most effective and comprehensive way to address the widespread social and economic harm caused by excessive medicalization. Barring that, the state could at least send a clear message in support of midwifery by issuing clinical guidelines recommending midwifery care for all low-risk pregnancies, funding the establishment of more midwifery practices, or adopting incentive programs to encourage midwifery care.

\section{CONCLUSION}

Pregnant women need meaningful and transformative birth experiences free of abuse and unnecessary medical intervention. They need supportive care that allows for safe and healthy birth outcomes. Instead, they are effectively forced to pay top dollar to give birth under a medical and technocratic model that only increases their chance of suffering significant injury or death. Rather than adopting meaningful solutions to its shockingly high rate of maternal and infant mortality, the state holds pregnant women entirely responsible for negative outcomes and criminalizes them for social problems. The private ordering of the doctor-patient relationship, the focus on individual rights and choice in birth, and the myth of the autonomous medical consumer combine to create a system in which the state is absolved of responsibility to address birth injury, despite the collective benefits obtained from the reproduction of society. We must instead envision a responsive state that provides meaningful support for pregnancy and birth by actively seeking to support midwifery and normalize birth without intervention. In this manner, we can find real solutions to the problem of birth injury and transform birth from an adversarial event to a celebratory one.

\footnotetext{
${ }^{355}$ Brown, supra note 173, at 27.
} 